\title{
Propuesta de regulación de la aportación al capital social en la sociedad cooperativa española: aportación dineraria y aportación no dineraria
}

(Proposal for regulation of contribution to share capital in Spanish cooperative society: monetary contributions and nonmonetary contributions)

Begoña Lagos Rodríguez ${ }^{1}$

Universidad de Castilla-La Mancha (España)

Sumario: I. Introducción. II. Concepto. III. Clases. 1. Aportaciones dinerarias. 1.1. Entrega. 1.2. Acreditación de la realidad. 2. Aportaciones no dinerarias. 2.1. Valoración. 2.1.1. Introducción. 2.1.2. Informe del experto independiente. 2.1.3. Responsabilidad solidaria de los miembros del Consejo Rector. 2.1.4. Ratificación por la Asamblea General. 2.2. Supuestos especiales de responsabilidad por aportaciones no dinerarias: entrega, saneamiento y transmisión de riesgos. 2.2.1. Aportaciones de bienes muebles o inmuebles o derechos asimilados a ellos. 2.2.2. Aportación de un derecho de crédito. 2.2.3. Aportación de empresa o establecimiento. 2.3. Continuidad de la cooperativa en la titularidad del bien o derecho aportado. IV. Conclusiones. V. Bibliografía.

Summary: I. Introduction. II. Concept. III. Classes. 1. Monetary contributions. 1.1. Delivery. 1.2. Reality accreditation. 2. Non-monetary contributions. 2.1. Valuation. 2.1.1. Introduction. 2.1.2. Independent expert report. 2.1.3. Joint and several liability of the members of the Governing Council. 2.1.4. Ratification by the General Assembly. 2.2. Special cases of liability for non-monetary contributions: delivery, defect repair and risk transmission. 2.2.1. Contribution of movable or immovable property or similar rights. 2.2.2. Contribution of a credit right. 2.2.3. Company or establishment contribution. 2.3. Continuity of the cooperative society in the ownership of the good or right contributed. IV. Conclusions. V. Bibliography.

Resumen: este artículo pretende analizar el régimen de la aportación social al capital de una sociedad cooperativa española distinguiendo entre apor-

1 Facultad de Ciencias Jurídicas y Sociales de Toledo. E-mail: begona.lagos@uclm.es 
taciones dinerarias y no dinerarias. A este respecto, el legislador ha tenido en cuenta, en términos generales, la normativa propia de las sociedades capitalistas. De tal forma, en los temas relacionados con el capital social y el patrimonio nos fijaremos, básicamente, en tal normativa, si bien, existen ciertas peculiaridades derivadas de la propia caracterización jurídica de la sociedad cooperativa respecto de las sociedades de capital. El objeto perseguido con este estudio será la formulación de una necesaria, como pretendemos evidenciar a lo largo de esta exposición, propuesta de regulación de la aportación al capital social en una sociedad cooperativa.

Palabras clave: aportación al capital social en una sociedad cooperativa española; aportaciones dinerarias y no dinerarias; crítica a la valoración de las aportaciones no dinerarias; propuesta de regulación.

Abstract: this paper studies the contribution to share capital in Spanish cooperative society. A distinction is made between monetary contribution and non-monetary contribution. In this regard, the legislator takes into account the regulation of the capital company. However, there are certain peculiarities of the cooperative society. The objective of this paper is to formulate a new proposal for regulation of contribution to share capital in cooperative society.

Keywords: contribution to share capital in Spanish cooperative society; monetary contributions and non-monetary contributions; critique of the valuation of non-monetary contributions to share capital; proposal for regulation. 


\section{Introducción}

En este artículo se pretende realizar un análisis de la aportación social en la sociedad cooperativa caracterizada por ser una sociedad de capital variable donde las personas, físicas o jurídicas, deciden asociarse libre y voluntariamente desarrollando una actividad empresarial para satisfacer unas necesidades de orden económico, social y cultural.

En la regulación de esta sociedad contamos, de un lado, con un ámbito estatal, Ley 27/1999, de 16 de julio, de Cooperativas (en adelante, LC) y Real Decreto 136/2002, de 1 de febrero, por el que se aprueba el Reglamento del Registro de Sociedades cooperativas; y de otro, con un ámbito de regulación autonómico². A tenor de éste, se optó por acudir a leyes especiales en lugar de adaptar, de hecho, el régimen propio de las sociedades de índole capitalista ${ }^{3}$ originando una

2 La antigua Ley 3/1987, de 2 de abril, General de Cooperativas adapta el régimen jurídico de las sociedades cooperativas a las exigencias del Estado de las Autonomías. Las Comunidades Autónomas han asumido la competencia exclusiva en esta materia, por lo que el ámbito de aplicación de nuestra actual LC ha sido ampliamente reformulado quedando limitado (art. 2 LC):

a) A las sociedades cooperativas que desarrollen su actividad cooperativizada en el territorio de varias Comunidades Autónomas, excepto cuando en una de ellas se desarrolle con carácter principal.

b) A las sociedades cooperativas que realicen principalmente su actividad cooperativizada en las ciudades de Ceuta y Melilla.

Vid., a tenor de la normativa autonómica: Ley 4/1993, de 24 de junio, de Cooperativas de Euskadi (LCPV); Ley 5/1998, de 18 de diciembre, de Cooperativas de Galicia (LCG); Ley 4/1999, de 30 de marzo, de Cooperativas de la Comunidad de Madrid (LCCM); Ley 4/2001, de 2 de julio, de Cooperativas de la Rioja (LCLR); Ley 4/2002, de 11 de abril, de Cooperativas de la Comunidad de Castilla y León (LCCyL); Ley 1/2003, de 20 de marzo, de Cooperativas de las Islas Baleares (LCIB); Ley Foral 14/2006, de 11 de diciembre, de Cooperativas de Navarra (LCFN); Ley 8/2006, de 16 de noviembre, de Sociedades Cooperativas de la Región de Murcia (LSCRM); Ley 11/2010, de 4 de noviembre, de Cooperativas de Castilla-La Mancha (LCCLM); Ley 4/2010, de 29 de junio, de Cooperativas del Principado de Asturias (LCPA); Ley 14/2011, de 23 de diciembre, de Sociedades Cooperativas Andaluzas (LCA); Ley 6/2013, de 6 de noviembre, de Cooperativas de Cantabria (LCCant); Decreto Legislativo 2/2014, de 29 de agosto, del Gobierno de Aragón, por el que se aprueba el texto refundido de la Ley de Cooperativas de Aragón (LCAR); Decreto Legislativo 2/2015, de 15 de mayo, del Consell, por el que se aprueba el texto refundido de la Ley de Cooperativas de la Comunidad de Valencia (LCCV); Ley 12/2015, de 9 de julio, de Cooperativas de la Comunidad Autónoma de Cataluña (LCCAT); Ley 9/2018, de 30 de octubre, de sociedades cooperativas de Extremadura (LSCEX).

3 Piénsese en la concomitancia existente entre el régimen de la aportación social en la sociedad cooperativa y la aportación social en las sociedades de capital, especialmente, en el caso de la sociedad de responsabilidad anónima. 
disparidad normativa que no responde adecuadamente a un mercado cada vez más globalizado 4 .

Nuestro legislador tuvo en cuenta, en lo que aquí importa, la normativa propia de las sociedades capitalistas. De tal forma, en los temas relacionados con el capital social y el patrimonio nos fijaremos, básicamente, en tal normativa, si bien, existen ciertas peculiaridades en la materia que devienen de la singularidad característica de la sociedad cooperativa respecto de las sociedades de capital. Tal singularidad es fruto de los principios cooperativos que tienen un claro contenido de índole económico. En el Congreso de la Alianza Cooperativa Internacional (ACl) celebrado en 1995 en Manchester se enuncian y se redactan los siguientes principios: adhesión voluntaria y abierta; gestión democrática por parte de los socios; participación económica de los socios; autonomía e independencia; educación, formación e información; cooperación entre cooperativas; interés por la comunidad.

De todos ellos, será el principio de adhesión voluntaria y abierta, conocido como principio de puertas abiertas ${ }^{5}$, el que mayor alteración cause en el régimen del capital social con respecto a las sociedades capitalistas. Como consecuencia de este principio, las cooperativas serán sociedades de capital variable donde los socios pueden entrar y salir de forma casi continua. De esta forma, la doctrina confiere un mayor protagonismo al capital material o valor contable, es decir, al valor efectivo de las aportaciones de los socios sobre el capital nominal, como la cifra fijada en los estatutos ${ }^{6}$. En todo caso, la variabilidad del capital no es absoluta, puesto que el capital sólo será variable hasta el límite fijado en los estatutos como capital social mínimo (el art. 45. 2 LC exige el total desembolso de éste desde la constitución de la sociedad). Por

4 Nuestra normativa ha de confrontarse con la legislación europea, Reglamento (CE) n. ${ }^{\circ}$ 1435/2003 del Consejo, de 22 de julio de 2003, relativo al Estatuto de la Sociedad Cooperativa Europea (SCE), que habrá de compaginarse con la abundante casuística propia de las distintas leyes autonómicas. Frente a la crisis financiera sufrida, las cooperativas europeas, cuyo estudio excedería de los límites propuestos en este trabajo, se han revelado como un instrumento muy valioso para paliar sus efectos. Así, se ha afirmado que este tipo de empresas son «una herramienta fundamental en el futuro económico de la Unión Europea». De este parecer, Carlos Vargas Vasserot, Gadea Soler Enrique y Fernando Sacristán Bergia, Derecho de las sociedades cooperativas. Introducción, constitución, estatuto del socio y órganos sociales (Madrid: La Ley, 2015), 45-46.

5 Vid., Carlos Vargas Vasserot, «El principio cooperativo de puertas abiertas (adhesión voluntaria y abierta). Tópico o realidad en la legislación y en la práctica societaria», CIRIEC-España, Revista jurídica de economía social y cooperativa, n. ${ }^{\circ} 27$ (2015): 133-174.

6 Sobre este particular, Francisco Vicent Chuliá, Ley General de Cooperativas, vol. 3. ${ }^{\circ}$. Artículos 67 al final (Madrid: EDERSA, 1994), 212. 
lo tanto, el capital mínimo de la cooperativa es fijo y la posterior alteración de éste requiere de una modificación estatutaria.

A tenor del Tercer principio formulado por la $\mathrm{ACl}$, participación económica de los socios, "Los miembros de la cooperativa contribuyen equitativamente al capital de su cooperativa y lo controlan democráticamente. Al menos parte de ese capital suele ser propiedad común de sus miembros. Estos suelen recibir una limitada compensación, si la hubiera, sobre el capital aportado como requisito de afiliación a la cooperativa. Los miembros destinan los excedentes para todos o algunos de los siguientes fines: desarrollar su cooperativa, posiblemente mediante el establecimiento de reservas, parte de las cuales al menos serían indivisibles; beneficiando a los miembros en proporción a sus transacciones con la cooperativa; y apoyando otras actividades aprobadas por los miembros». Este Tercer principio, como así ha señalado nuestra doctrina, integra dos reglas distintas. "La primera hace referencia al capital (en un sentido amplio), su conformación, titularidad y compensación. La segunda se refiere a los resultados del ejercicio y en particular a su distribución ${ }^{7}$. En todo caso, nos interesa destacar que, como así se deduce de este Tercer principio, la distribución de los excedentes no ocurre en función del capital social aportado por los socios, sino en proporción a la actividad de éstos.

De esta forma, aunque el capital social no sirva, a diferencia de lo que ocurre en el marco de las sociedades de capital, como instrumento medidor de la organización corporativa y económica de la sociedad, eso no quiere decir que carezca de toda importancia en cuanto a la determinación de la estructura de la propia sociedad ${ }^{8}$.

Si el capital social se constituye por las aportaciones de los socios, art. 45.1 LC, tales aportaciones se pueden clasificar en función del contenido de la aportación distinguiendo entre aportaciones dinerarias y no dinerarias — donde la influencia de la regulación característica de las

7 Así es señalado expresamente, Gemma Fajardo García, «Orientaciones y aplicaciones del principio de participación económica», CIRIEC-España, Revista de Economía Pública, Social y Cooperativa, n. ${ }^{\circ} 27$ (2015): 212.

8 Existen distintas normas que reflejan la importancia del capital social en la sociedad cooperativa; vid., entre otros, Rodrigo Uría González y Aurelio Menéndez Menéndez, Curso de Derecho Mercantil, Tomo I (Madrid: Civitas, 1999), 1294. Como ejemplos citaremos el art. 45.2 LC que, teniendo presente la necesidad de establecer una cifra mínima de capital social, obliga a que tal cifra esté totalmente desembolsada desde el momento de la constitución de la sociedad siendo fijada en los estatutos; o el art. 48.8 LC, ya que si el capital social, por circunstancias, cayese por debajo del mínimo fijado estatutariamente «la cooperativa deberá disolverse a menos que en el plazo de un año se reintegre o se reduzca el importe de su capital social mínimo en cuantía suficiente». 
sociedades de capital toma especial protagonismo- y en función de su necesidad distinguiendo entre aportaciones obligatorias y aportaciones voluntarias criterio clasificatorio propio de la sociedad cooperativa. Pero igualmente se pudiera atender a otros criterios de clasificación de las aportaciones sociales distinguiendo entre aportaciones reembolsables y no reembolsables y, atendiendo al carácter subjetivo, se podría distinguir entre aportaciones realizadas «por el socio cooperador o usuario, por los socios de trabajo, por los socios temporales o por los colaboradores ${ }^{9}$. Las propias limitaciones del trabajo propuestos motivan que, de estos criterios de clasificación, únicamente vayamos a tratar los relativos al contenido de la aportación.

Abordaremos, a continuación, el estudio del régimen jurídico resultante a tenor de la aportación dineraria y aportación no dineraria acudiendo al estudio comparativo de la LC con el Real Decreto Legislativo 1/2010, de 2 de julio, por el que se aprueba el texto refundido de la Ley de Sociedades de Capital ${ }^{10}$, respondiendo a ello la sistemática adoptada para, de esta forma, estar en posición de emitir una serie de consideraciones reasuntivas, en cuanto a las aportaciones dinerarias y no dinerarias, que nos conduzcan a la formulación de una propuesta de regulación de la sociedad cooperativa. A este respecto, debemos tener en cuenta que nuestro derecho de sociedades se ha sometido a una profunda remodelación fruto, en parte, a las exigencias de adecuación a las directivas comunitarias y, en parte, por la propia evolución práctica de las instituciones propias del derecho de sociedades, de manera, que las sociedades cooperativas no pueden permanecer ajenas a tal evolución y consiguiente remodelación de su régimen jurídico. En el marco de un mercado globalizado, la confluencia entre la ley estatal y las distintas leyes autonómicas, además de las diferentes normas sectoriales que afectan, entre otros, al régimen fiscal, al crédito... es causa de una gran dispersión normativa que no casa bien con el referido mercado globalizado. Por ello, tal remodelación es, a nuestro juicio, absolutamente necesaria. Téngase presente que -en respuesta a la Orden de 6 de noviembre de 2014, por la que se constituye en el seno de la Sección de Derecho mercantil de la Comisión general de Codificación una ponencia para la revisión del régimen jurídico de las cooperativas - surge una Propuesta de la Ponencia para la elaboración de un texto articulado de revisión de su régimen en julio de 2017.

9 Vid., Francisco José Torres Pérez, Régimen jurídico de las aportaciones sociales en la sociedad cooperativa (Navarra: Aranzadi, 2012), 47-48.

10 En adelante, LSC. 


\section{Concepto de aportación social}

A tenor del art. 45.1 LC, el capital social se constituye mediante las aportaciones obligatorias y voluntarias de los socios. De este artículo, como podría afirmarse igualmente del art. 1.2 (sociedad de responsabilidad limitada) y 1.3 (sociedad anónima) LSC que determinan ambos la integración del capital social por las aportaciones de los socios, podría deducirse la estrecha relación que existe entre capital y aportaciones sociales, de forma que «(...) disciplinar la constitución, al menos originaria, del capital social significa dictar reglas a propósito de las aportaciones de los socios que indiquen las características de la prestación que cada uno de ellos está obligado a efectuar para entrar a formar parte de la sociedad (quantum, quandum, quomodo, quid)» ${ }^{11}$.

Desde el punto de vista jurídico ${ }^{12}$ no es posible hallar un concepto unívoco de aportación social ${ }^{13}$ siendo preciso que se acuda a los artículos 1665 CC y 116 CCom entendiendo por aportación, básicamente, la prestación idónea a la consecución del fin social ${ }^{14}$. Sin embargo, una definición genérica como ésta, válida para todas las sociedades, sean civiles o mercantiles, parece desconocer las específicas necesidades de cada tipo social pues, dependiendo de ellas, el patrimonio de la sociedad adoptará una u otra estructura que, a su vez, determinará la idoneidad de una prestación para ser calificada como

11 Vid., Gustavo Olivieri, I conferimenti in natura nella società per azioni (Padova: Cedam, 1989), 84.

12 Prescindiremos de la perspectiva económica que considera la aportación como participación en la vida empresarial.

13 Llama la atención sobre este particular, Pedro José Rubio Vicente, La aportación de empresa en la sociedad anónima (Valladolid: Lex Nova, 2001), 63.

14 En este sentido, vid. Joaquín Garrigues, Tratado de Derecho Mercantil, Tomo I, vol. 1. ${ }^{\circ}$ (Madrid: Revista de Derecho Mercantil, 1947), 440; ÍDEM, «Teoría general de las sociedades mercantiles», $R D M, n{ }^{\circ} 132$ (1974): 212; José Girón Tena, Derecho de Sociedades, Tomo I, Parte general, sociedades colectivas y comanditaria (Madrid: GT, 1976), 213-215, para quien, dado que el término de aportación es muy restringido, es preferible considerar a la aportación en el sentido amplio de colaboración en el fin común; Ignacio Lojendio Osborne, "Aportaciones sociales (artículos 36 a 41 LSA)», en Aportaciones sociales y dividendos pasivos, artículos 36 a 46 de la Ley de Sociedades Anónimas, tomo III, vol. 3. ${ }^{\circ}$, dir. por Uría, Menéndez y Olivencia (Madrid: Civitas, 1994), 18-19; ÍDEM, "Aportaciones sociales (artículos 18 a 21 LSRL)», en Régimen Jurídico de la Sociedad de Responsabilidad Limitada, tomo XIV, vol. 1. ${ }^{\circ}$ A, dir. por Uría, Menéndez y Olivencia (Madrid: Civitas, 1999), 521-522; Esperanza Gallego Sánchez, "Las aportaciones en la sociedad de responsabilidad limitada», RdS, n. ${ }^{\circ} 5$ (1995): 81. 
aportación en el marco de un tipo social concreto. De ahí la dificultad de hallar un concepto único de aportación social ${ }^{15}$.

Partiendo del hecho de que la aproximación a la aportación social debe tener lugar en función de las necesidades de cada tipo social, pues la admisión de toda prestación útil a la consecución del fin social sólo tiene sentido tratándose de sociedades personalistas donde los socios responden personal y subsidiariamente de las deudas sociales, pero no en las sociedades de capital, ya que en éstas los acreedores cuentan con el capital social como garantía del cobro de sus créditos, ni tampoco en las sociedades cooperativas, podemos distinguir entre aportación como operación jurídica consistente en la puesta en común de bienes o derechos a través de un desplazamiento patrimonial de éstos a la sociedad -acción que constituye el contenido de la obligación del socio derivada del contrato de sociedad-y aportación como aquello que se pone en común o prestación que un socio se compromete a realizar en favor de la sociedad.

Desde esta última perspectiva, es decir, entendida la aportación como la prestación del socio, surge la existencia de una doble acepción del término aportación. En primer lugar, éste puede hacer referencia a la obligación de efectuar la prestación social prometida. En segundo lugar, el término aportación puede interpretarse como la prestación social ya realizada.

En el marco de las sociedades capitalistas, tal diversidad de acepciones adquiere protagonismo en la determinación del momento a partir del cual se entiende realizada la aportación. En todo caso, será necesario que se parta de las necesidades de cada tipo social. Así, tratándose de una sociedad de responsabilidad limitada el capital debe estar totalmente desembolsado desde su origen, artículo 78 LSC. Por lo tanto, no cabría distinguir entre la asunción de la obligación de aportar y la aportación propiamente dicha, ya que no ha lugar a la entrega

15 En el sentido indicado en el texto, Inés Fernández Fernández, Aportaciones no dinerarias en la sociedad anónima (Navarra: Aranzadi, 1997), 33; Rubio, La aportación..., 69-70. De distinto parecer, vid. Lojendio, «Aportaciones sociales (artículos 36...)», 20-22, quien admite la existencia de un concepto amplio de aportación, válido para todo el Derecho de sociedades, entendido no sólo como contribución patrimonial al fondo común, sino también como toda colaboración destinada a la consecución del fin social, de manera que ni el concepto, ni siquiera su objeto, puede variar en función del carácter capitalista o, en su caso, personalista de la sociedad. De la misma opinión, Gallego, «Las aportaciones.... 83.

Pese a lo referido, si difícil resulta hallar un concepto único de aportación social, que el objeto de la aportación no deba ser comprendido en orden a las especialidades de cada tipo social parece insostenible. Vid., en cuanto a la diversidad del objeto a tenor del tipo social, Girón, Derecho de sociedades..., 216. 
diferida de las aportaciones sociales. Por su parte, si estamos ante una sociedad anónima, en virtud del artículo 79 LSC, se distingue claramente entre suscripción y desembolso de capital social siendo dos las posibles interpretaciones. De un lado, cabría considerar que la aportación se perfecciona en el momento en que el aportante adquiere la condición de socio, de manera que, con el desembolso mínimo exigido por la Ley, ya existiría aportación. De otro, podría interpretarse que la aportación no se consuma hasta que se produce el desembolso del contravalor correspondiente a las acciones suscritas ${ }^{16}$. En todo caso, coincidimos con aquel sector de la doctrina que entiende que carece de relevancia práctica la existencia de ambas acepciones ${ }^{17}$.

La distinción entre estas dos acepciones del término, aportación referida a la obligación de efectuar la prestación social comprometida y aportación como prestación social realizada, la encontraremos también en la sociedad cooperativa en virtud de los arts. 10 (escritura de constitución) y 11 (contenido de los estatutos) de la LC ${ }^{18}$. Cierto es que, a tenor del art. 45.2 LC, los estatutos fijarán el capital social mínimo con que puede constituirse y funcionar la cooperativa, que deberá estar totalmente desembolsado desde su constitución ${ }^{19}$. Sin embargo, para el régimen de las aportaciones obligatorias, el art. 46.3 LC señala que de-

16 Partidarios de la interpretación obligacional de la aportación social, vid. Alejandro Bérgamo, Sociedades Anónimas. Las acciones, Tomo I (Madrid: Prensa Castellana S.A., 1970), 426; Girón, Derecho de sociedades..., 214, que parece inclinarse por esta interpretación, pues afirma «cuando se dice que no hay aportación hasta que se consuma la entrega, se utiliza una noción dudosamente útil a los efectos científicos», si bien, asimismo señala que «cuando se trata de distinguir aportación, obligación de aportar, entrega, obligación de entrega, nos queda igualmente un concepto de aportación muy escasamente empleable (...)»; Vicente Mambrilla Ribera, «Fundación con aportaciones in natura», en Derecho de Sociedades Anónimas, I, La fundación, coord. por Alberto Alonso Ureba (Madrid: Civitas, 1991), 742-743; Víctor Manuel Garrido de Palma, «Régimen de las aportaciones sociales», en Tratando de la sociedad de responsabilidad limitada, coord. por José Cándido Paz-Ares (Madrid: Fundación Cultural del Notariado, 1997), 364-365; Raúl Bercovitz Álvarez, La aportación de derechos de propiedad industrial al capital de las sociedades anónimas. Breve referencia a esta aportación en las sociedades limitadas (Navarra: Aranzadi, 1999), 28-32; Pedro José Rubio Vicente, La aportación..., 64-65. Partidarios de aportación como prestación realizada o consumada, Joaquín Garrigues, Tratado..., 440441; Antonio de la Esperanza Martínez-Radio, «Tradición instrumental y aportación social», RDM, n. 78 (1960): 486-488; FERNÁNDEZ, Aportaciones..., 35-37.

17 Lojendio, «Aportaciones sociales (artículos 18...)», 521-522.

18 De este parecer, Miguel Ángel Pendón Meléndez, «El capital social. Aportaciones al capital social», en Tratado de Derecho de sociedades cooperativas, Tomo I, dir. por Juan Ignacio Peinado Gracia (Valencia: Tirant lo Banch, 2019), 686-687.

19 Sobre este particular, vid., Alfredo Ávila de la Torre, «Aspectos jurídico-mercantiles de la Sociedad Cooperativa. Breves consideraciones», en Economía social y cooperativismo, dir. por Purificación Morgado Panadero (Valladolid: Lex Nova, 2006), 100. 
berán desembolsarse, al menos, en un 25 por 100 en el momento de la suscripción y el resto en el plazo que se establezca por los Estatutos o por la Asamblea General, es decir, qué si inicialmente prevé la Ley el desembolso íntegro del capital social mínimo, más tarde dispone un desembolso mínimo de la aportación obligatoria. Por lo tanto, si se ha alcanzado la cifra mínima de capital social, se admite el desembolso mínimo de las aportaciones obligatorias, razón por la cual cabe distinguir entre las mencionadas acepciones de la aportación social.

En definitiva, se puede concluir el carácter esencial de la aportación que constituye un elemento determinante del contrato de sociedad y significa la obligación que atañe a todos los socios de realizar prestaciones a fin de formar un fondo patrimonial separado y participar en el riesgo inherente a la actividad empresarial. Por consiguiente, la aportación constituye un requisito indispensable para el nacimiento de la sociedad y para la consecución del fin social. Esta afirmación es válida también en el ámbito de las sociedades cooperativas, pues éstas ejercen una función empresarial y la responsabilidad de sus socios está limitada al capital social, de forma que el ingreso en una sociedad cooperativa queda supeditado al cumplimiento de la obligación de realizar las aportaciones convenidas en la escritura de constitución teniendo presente que la condición de socio también pudiera deducirse de la realización o abono de otras cuantías que no formarán parte del capital social de la sociedad y que se arbitran como un medio para financiar dicha sociedad como son las cuotas de ingreso o las cuotas periódicas ${ }^{20}$.

Ahora bien, lo cierto es que encontramos también rasgos característicos de la aportación social a la sociedad cooperativa que la distinguen claramente de las sociedades de capital. Así, la aportación no supone el conjunto de derechos y obligaciones de los socios ${ }^{21}$ dudándose, incluso, de la naturaleza de éstas, es decir, se cuestionan si son

20 Tales medios de financiación pueden referirse tanto a los socios de la cooperativa como a personas ajenas a la cooperativa y, a tenor del art. 52 LC, no forman parte del capital social. En cuanto a estos medios de financiación son: 1) las cuotas de ingresos y/o periódicas establecidas por los Estatutos o la Asamblea General (art. 52, Ley 27/1999, de 16 de julio, de Cooperativas) teniendo presente que el importe de las cuotas de ingreso de los nuevos socios, no podrá ser superior al $25 \%$ del importe de la aportación obligatoria al capital social que se le exija para su ingreso en la cooperativa; 2) los bienes de cualquier tipo entregados por los socios para la gestión cooperativa; 3 ) los pagos para la obtención de los servicios cooperativizados. Vid., entre otros, Francisco Javier Valenzuela Garach, «El capital social. Aportaciones que no forman parte del capital social», en Tratado de derecho de sociedades cooperativas, Tomo I, dir. por Juan Ignacio Peinado García (Valencia: Tirant lo Banch, 2019), 752-767.

21 Si los derechos y obligaciones de un socio integran su condición, la aportación al capital social de una cooperativa no responde a este conjunto de derechos y obligacio- 
auténticas aportaciones, ya que «no sirven para medir la intensidad de los derechos económicos ni políticos de los cooperadores»22. También, como particularidad de la aportación social a la sociedad cooperativa, cabe afirmar que ésta no constituye una parte alícuota del patrimonio total, sino «del patrimonio neto repartible reflejado en el pasivo del balance por el capital social, dentro de los fondos propios» ${ }^{23}$, con la consiguiente trascendencia para el caso de liquidación de la sociedad ${ }^{24}$.

\section{Clases de aportaciones}

$\mathrm{Ni}$ en atención a la diversa tipología societaria — sea ésta civil o mercantil - ni, como era de esperar, acudiendo a la normativa sobre sociedades cooperativas (estatal o autonómica) encontraremos una definición legal acerca de la aportación social, lo que contribuye a la existencia de una confusión terminológica en torno al concepto de la aportación social, que incide también en el criterio clasificatorio de la propia aportación, por parte del legislador cooperativo, puesto que, en ocasiones, utiliza el término aportación para designar el objeto de la prestación del socio; otras veces, con el referido término se hace referencia a las participaciones en el capital social, es decir, a los títulos que el socio recibe de la sociedad como consecuencia de la prestación realizada e incluso al conjunto de derechos deducidos de su condición de socio o asociado. Como consecuencia, de la mencionada confusión terminológica encontraremos en sede de sociedades cooperativas un doble criterio clasificatorio. De un lado, podemos clasificar las aportaciones sociales a la cooperativa, según se ha referido anteriormente, atendiendo a la aportación como objeto, es decir, acudiendo, en definitiva, al contenido de la aportación social. Así distinguiremos entre aportación dineraria y aportación no dineraria. De otro, podemos diferenciar entre aportaciones obligatorias y aportaciones voluntarias a tenor del carác-

nes. Vid., a este respecto, María del Carmen Pastor Sempere, Los recursos propios en las sociedades cooperativas (Madrid: EDERSA, 2002), 152.

22 Así lo entiende, Torres, Régimen..., 42, haciéndose eco, en la cuestión, de Francisco Vicent Chuliá, "Análisis crítico del nuevo Reglamento de Cooperación (Decreto 2396/1971 de 13 de agosto. «B.O.E.» de 9 de octubre)», RDM, n. ${ }^{\circ}$ 125-126 (1972): 456.

23 María José Morillas Jarillo y Manuel Ignacio Feliú Rey, Curso de Cooperativas, Tomo I (Madrid: Tecnos, 2018), 462.

24 Vid., sobre este particular, Manuel Paniagua Zurera, La sociedad cooperativa. Las sociedades mutuas de seguros y las entidades mutuales de previsión social (Madrid: Marcial Pons, 2005), 247, quien llama la atención sobre el hecho de que una parte del activo sea de carácter irrepartible. 
ter necesario o no de las mismas. En todo caso, este último criterio clasificatorio excedería de los términos del trabajo propuesto 25 .

Distingue, art. 45.4 LC, entre aportaciones dinerarias y aportaciones no dinerarias al disponer, el artículo en cuestión, que «Las aportaciones de los socios al capital social se realizarán en moneda de curso legal. No obstante, si lo prevén los Estatutos o lo acordase la Asamblea General, también podrán consistir en bienes y derechos susceptibles de valoración económica». De este artículo podemos concluir que será precisamente la aportación dineraria la que con mayor frecuencia esté presente en la práctica, ya que no presenta dificultades valorativas, puesto que el propio dinero será una medida de valor ${ }^{26}$, mientras que en los estatutos o la asamblea general de la sociedad cooperativa se podrían acordar la presencia de aportaciones no dinerarias.

\section{Aportación dineraria}

La aportación dineraria resulta, como así se ha señalado, la más frecuente en la práctica, ya que, descartado el tema valorativo, no presenta mayores problemas que el de su acreditación, exigencia requerida tanto si se trata de aportaciones dinerarias como no dinerarias. El legislador, por lo tanto, sólo atiende al aseguramiento de la realidad o efectividad de su realización, es decir, a la entrega de las aportaciones dinerarias y a la acreditación de éstas. A tal efecto, el art. 10.1.f) LC exige que la escritura de constitución de la sociedad cooperativa contenga una acreditación de los otorgantes de que el importe total de las aportaciones desembolsadas no es inferior al del capital social mínimo establecido estatutariamente. A su vez, el art. 10.1.d) LC exige, igualmente, la constancia de la acreditación por los otorgantes de haber suscrito la aportación obligatoria mínima al capital social para ser socio y de haberla desembolsado, al menos, en la proporción exigida estatutariamente. Tales menciones son exigibles tanto si estamos en presencia de una aportación dineraria como de una aportación no dineraria.

25 Se acoge, en este contexto, la clasificación más significativa de las aportaciones en la sociedad cooperativa, pero teniendo en cuenta que éste no es el único criterio de clasificación. Vid., a este respecto, Torres, Régimen..., 47-48, quien distingue, según se ha referido en un momento anterior de esta exposición, entre aportaciones dinerarias y no dinerarias; aportaciones obligatorias y voluntarias; aportaciones realizadas por el socio cooperador o usuario, por los socios de trabajo, por los socios temporales o por los colaboradores; y, por último, aportaciones al capital social reembolsables y aportaciones cuyo reembolso puede ser rehusado incondicionalmente por la cooperativa.

26 Lojendio, "Aportaciones sociales (artículos 36...», 37. 


\subsection{ENTREGA}

En cuanto a la forma de realización de la aportación dineraria, ésta puede suceder mediante entrega de efectivo, transferencia bancaria o cheque. Es este último supuesto, la entrega de cheque, el que mayores objeciones ha planteado por su condición de título de crédito, si bien, se ha distinguido entre la entrega de un título a la sociedad, lo que debiera ser entendido como aportación no dineraria, y la entrega del cheque al notario, en cuyo caso, hasta que el notario no reciba el aviso del banco de que las cantidades correspondientes han sido ingresadas, no se registra a nombre de la sociedad, momento en el que nos hallaremos ante una aportación dineraria.

En todo caso, la aportación dineraria (art. 45.4 LC) debe ser realizada en moneda de curso legal. Como nada se dice respecto de la aportación dineraria en moneda extranjera, acudiremos por analogía a la normativa de las sociedades de capital27. A tenor del art. 61 LSC (párrafos primero y segundo) las aportaciones deben establecerse en euros y si la aportación fuese en otra moneda, se determinará su equivalencia en euros con arreglo a la ley. Por consiguiente, será necesario acudir a la Ley de Enjuiciamiento Civil que en su art. 577.2 establece que la conversión se realizará conforme al «cambio oficial al día del despacho de la ejecución». Ahora bien, se plantea la necesidad de distinguir entre tres momentos diferentes de la vida social: momento constitutivo, sucesivos aumentos de la aportación social y momento relativo al pago de los dividendos pendientes. En el caso de la constitución de la sociedad será la fecha del otorgamiento de la escritura fundacional la que determine la fecha de cotización. En el supuesto de aumento de capital atenderemos a la ejecución de dicho aumento ${ }^{28}$ y, en el caso de los desembolsos pendientes, al desembolso efectivo de la aportación sin necesidad de esperar a la formalización de éste ${ }^{29}$. Por otra parte, si se trata de una divisa sin cotización en nuestro país debe

27 Así lo entiende, entre otros, Torres, Régimen..., 53.

28 Vid., José María Carrau Carbonell, «Aportaciones sociales», en Tratado de sociedades de Capital: comentario judicial, notarial, registral y doctrinal de la Ley de Sociedades de Capital (Arts. 1 a 316), Tomo I., coord. por Leticia Ballester Azpitarte (Navarra: Thomson Reuters Aranzadi, 2017), 411, para quien sería posible que se flexibilizara este criterio "y tomar el día de la Junta General en la que se adopta el acuerdo de aumentar el capital mediante aportaciones dinerarias» como determinante.

29 Vid., Rafael Bonardell Lenzano y Ricardo Cabanas Trejo, «De las aportaciones y de las adquisiciones onerosas», en Comentarios a la Ley de Sociedades Anónimas, vol. I, coords. por Ignacio Arroyo Martínez, José Miguel Embid Irujo y Carlos Górriz López (Madrid: Tecnos, 2009), 429; Lojendio, «Aportaciones sociales (artículos 18...)», 543; Torres, Régimen..., 53. 
«buscarse una moneda puente que cotice en España y en el país de la moneda que se aporte ${ }^{30}$. También se ha sostenido que, en este supuesto, estaríamos ante una aportación no dineraria, solución que, a nuestro juicio, nos parece más acertada 31 .

\subsection{ACREDITACIÓN DE LA REALIDAD}

En cuanto a la acreditación de tales aportaciones dinerarias ${ }^{32}$, en el contexto de las sociedades cooperativas no contamos con un medio establecido al efecto de garantizar la realidad y el desembolso de tales aportaciones, sino que se acudirá, por analogía, a lo dispuesto a tenor de las sociedades de capital $^{33}$ teniendo presente que, ya que la aportación dineraria no suscita problema valorativo alguno, el legislador

30 El entrecomillado corresponde a Lojendio, «Aportaciones sociales (artículos 18...)», 543.

31 De este parecer, Bonardell y Cabanas, «De las aportaciones...», 430.

32 Con la acreditación referida se pretende garantizar la efectiva integración del capital social dando respuesta a la función de garantía que éste está llamado a cumplir. Tradicionalmente, se ha atribuido al capital social una función de garantía, de manera que, en las sociedades de capital, las aportaciones sociales debieran servir, prioritariamente, como garantía frente al acreedor social. Vid., acerca de la concepción tradicional del capital social en su función de garantía, Garrigues, Tratado..., 634 y ss. y 643 y ss.; Bérgamo, Sociedades Anónimas..., 121-122; Antonio Pérez de la Cruz, La reducción del capital social en sociedades anónimas y de responsabilidad limitada (Zaragoza: Real Colegio de España en Bolonia, 1973), 43-45. Desde esta perspectiva, se considera que el capital social constituye una "cifra de retención» del patrimonio en favor del acreedor. Supone el montante mínimo que el patrimonio debe alcanzar y que ha de ser conocido por los terceros que actúan en el tráfico jurídico-económico con la sociedad, ya que representa la garantía de las operaciones con la misma. Concebido de esta forma el capital social, es fácil deducir que estamos en presencia de un correctivo que se arbitra en virtud del principio de responsabilidad limitada de los socios, característico de las sociedades capitalistas y también presente cuando hablamos de sociedades cooperativas, donde el capital social aparece como instrumento de protección de terceros. El capital, sinónimo de cifra de retención sobre el patrimonio, equivale a la función dinámica de garantía superpuesta a la función estática, consistente en la publicidad registral que da acceso a terceros al conocimiento de esta cifra de retención limitativa de la responsabilidad de los socios por las deudas sociales. Es más, para un sector de nuestra doctrina, la función de garantía no responde únicamente a la defensa de los intereses de los acreedores sociales, sino también de los accionistas y de la empresa social.

33 Existe una abundante literatura jurídica acerca de las aportaciones dinerarias en el marco característico de las sociedades de capital, vid., como ejemplo, Lojendio, «Aportaciones sociales (artículos 36...)», 59-72; ÍDEM, «Aportaciones sociales (artículos 18...)», 542-572; Carrau, "Aportaciones...», 405-413. En el caso de las sociedades cooperativas, vid., entre otros, María Luisa Llobregat Hurtado, Mutualidad y empresas cooperativas (Barcelona: Librería Bosch, 1990), 247-248; Paniagua, La sociedad cooperativa..., 252. 
sólo atiende, con buen criterio, al aseguramiento de la realidad o efectividad de su realización, para lo cual, ante notario autorizante deberá acreditarse la realidad de la aportación mediante certificación de depósito de las correspondientes cantidades depositadas, o por su entrega para que aquél lo constituya a nombre de la sociedad, art. 62 LSC aplicable por analogía, lo que ha de suponer, al margen de las distintas responsabilidades de tipo profesional de los intervinientes ante supuestos tales como el depósito simulado, la falta de entrega a favor de la sociedad de la cantidad depositada, etc., garantía suficiente de la realidad de tales aportaciones. Consecuentemente, se arbitran dos sistemas de acreditación ${ }^{34}$.

El primero de ellos se basa en la acreditación del depósito del dinero a nombre de la sociedad en una entidad de crédito ${ }^{35}$ que no debe ser necesariamente española. Esta certificación bancaria debe hacerse a nombre de la sociedad, en nuestro caso, cooperativa ${ }^{36}$. Lo normal sería que se abriese una cuenta corriente a nombre de la sociedad en constitución, de manera que, antes del otorgamiento de la escritura de constitución, las cantidades ya fuesen ingresadas y la entidad de crédito sólo debiera certificar dichos ingresos siendo, este certificado de depósito, entregado al notario. A su vez, el notario tiene que dar fe de la exhibición y entrega de estos certificados que son incorporados a la escritura de constitución, de aumento o de los sucesivos desembolsos, de manera que no será posible que se solicite el reintegro. La vigencia de la certificación será de dos meses a contar desde su fecha (art. 62.3 LSC). Por su parte, la fecha del depósito no puede ser anterior en más de dos meses al otorgamiento (arts. 132.1 y 189.1 Real Decreto 1784/1996, de 19 de julio, por el que se aprueba el Reglamento del Registro Mercantili37). En cuanto a la cancelación del depósito, el

34 Según la RDGRN, de 4 de noviembre de 2011, no se puede acreditar la aportación dineraria por otros medios diferentes a los previstos en el art. 62 LSC, lo que resultaría aplicable también al caso de la sociedad cooperativa.

35 A tenor del art. 1.2 Ley 10/2014, de 26 de junio, de ordenación, supervisión y solvencia de las entidades de crédito, tienen la consideración de entidades de crédito los bancos, las cajas de ahorro, las cooperativas de crédito y el Instituto de Crédito Oficial.

36 Como así señala nuestra doctrina, esta denominación es confusa puesto que «no se trata de un certificado de depósito bancario», ya que ni circula, ni puede emitirse a la orden, sino que su finalidad será, en el marco del principio de integridad del capital social, responder del cumplimiento del principio de integridad del capital social. De este parecer, Esperanza Gallego Sánchez, "Acreditación de la realidad de las aportaciones», en Comentario de la Ley de Sociedades de Capital, Tomo I, dirs. Ángel José Rojo Fernández Río y Emilio M. Beltrán Sánchez (Navarra: Thomson Reuters-Civitas, 2011), 589.

37 En adelante, RRM. 
art. 62.3 LSC dispone que mientras no transcurra el período de vigencia de la certificación, la cancelación del depósito por quien lo hubiera constituido exige la previa devolución de la certificación a la entidad de crédito emisora.

El segundo sistema de acreditación de las aportaciones dinerarias del art. 62 LSC — teniendo presente que no se admiten, fuera de estas dos maneras de acreditar la realidad de las aportaciones dinerarias, otro sistema de acreditación ${ }^{38}$ - será la entrega del dinero en efectivo al notario para que éste constituya el depósito. Tal sistema de acreditación, entrega física del dinero, es menos común que la acreditación del depósito del dinero a nombre de la sociedad en una entidad de crédito.

En tal supuesto, el notario recibe la cantidad asignada efectuando un depósito en la cuenta bancaria a nombre de la sociedad cooperativa en cuestión. Sin embargo, la Ley no despeja la cuestión relativa al plazo en que se debe constituir este depósito. Así, será necesario acudir, por analogía, a los arts. 132.2 y 189.2 RRM, de donde deducimos que la solicitud de constitución del depósito debe ser consignado en la escritura, de manera que el notario no podrá actuar de oficio ${ }^{39}$, y que el notario debe constituir el depósito en un plazo de cinco días hábiles para hacerlo constar, de esta forma, en la escritura pública por medio de diligencia separada.

En cuanto a esta segunda forma de acreditar la realidad de las aportaciones dinerarias se ha considerado que es «la opción que mejor

38 Vid., RDGRN, de 4 de noviembre de 2011, en la que se declara: «el legislador societario ha encomendado siempre de forma exclusiva el control de existencia efectiva, de la realidad de las aportaciones dinerarias al notario autorizante del correspondiente instrumento público en que se formalice la prestación de tal contravalor del capital social (escritura fundacional, de aumento de capital o de desembolso de dividendos pasivos). De manera tasada se impone que esta comprobación directa la haga el notario, ya sea a través de la certificación (que se unirá a la escritura) justificativa del depósito de las sumas dinerarias en una entidad de crédito a nombre de la sociedad, o bien, en caso de recepción por éste de aquellas sumas, mediante el depósito que haga de las mismas a nombre de aquélla, debiendo quedar la oportuna constancia documental, según el sistema seguido, en los términos previstos en el artículo 62.1 LSC».

39 A este respecto, vid. Carrau, "Aportaciones...», 411, para quien el Notario deberá actuar siempre a requerimiento de parte planteándose la duda de si es necesario que, para esa entrega, sea autorizada un acta. El autor referido llega a la conclusión de que no es necesaria y esgrime dos razones al respecto: "desde el punto de vista teórico, porque la norma especial, que es el RRM, prevé que se consigne el depósito en la escritura, y debe prevalecer, como señala el art. 216, párrafo segundo del Reglamento Notarial, y desde el punto de vista práctico, porque las condiciones de la entrega, como la identidad del depositante o la cantidad, van a costar en la propia escritura pública, que dará fe de que se ha realizado». 
garantiza la realidad del desembolso ${ }^{40}$, sin embargo, lo cierto es que resulta bastante frecuente que, tras ello, se proceda a retirar los fondos, de manera que el control realizado por el notario resultaría inútil.

Ahora bien, aunque no se prevé, en el contexto de la sociedad cooperativa, ningún sistema encaminado a acreditar la realidad y el desembolso de la aportación dineraria debiendo, en consecuencia, acudir al ámbito de las sociedades de capital, alguna de nuestras leyes autonómicas sí disponen la incorporación a la escritura constitutiva del resguardo acreditativo del depósito en entidad de crédito, como medio de constatar la realidad de la aportación no dineraria. Tal sería el caso del art. 12.2 d) LCCM; art. 14.2 d) LSCRM; art. 13.2 d) LCCLM; y del art. 18.2 c) LSCEX.

Por último, aunque se haya de acudir por analogía al régimen de las sociedades de capital, debemos tener en cuenta la discrepancia de tal régimen en cuanto a la actuación del notario en el contexto de la sociedad anónima y de la sociedad de responsabilidad limitada, ya que en virtud de la Ley 14/2013, de 27 de septiembre, de apoyo a los emprendedores y su internacionalización, cuando se constituye una sociedad de responsabilidad limitada el control es vaciado de contenido, puesto que, a tenor del art. 15.4 y del art. 16.2 de la referida Ley, «no será necesario acreditar la realidad de las aportaciones dinerarias si los fundadores manifiestan en la escritura que responderán solidariamente frente a la sociedad y frente a los acreedores sociales de la realidad de las mismas» ${ }^{41}$.

40 Vid., Torres, Régimen..., 56.

41 Considera Eduardo Valpuesta Gastaminza, Comentarios a la Ley de Sociedades de Capital: estudio legal y jurisprudencial (Barcelona: Bosch, 2015), 188-189, criticable que un cambio de tal importancia se haya hecho efectivo fuera de la propia LSC. Ahora bien, al margen de esta crítica, a nuestro juicio esta previsión resulta muy acertada.

Piénsese que el art. 77 LSC prevé la responsabilidad solidaria de los fundadores de una sociedad anónima frente a la sociedad, los accionistas y los terceros, en lo que aquí importa, por la realidad de las aportaciones sean dinerarias o no dinerarias pese a que, para este último supuesto, se prevea el obligatorio sometimiento a valoración pericial. Dado que no existe un precepto paralelo al art. 77 LSC que resulte aplicable a las sociedades de responsabilidad limitada, de una interpretación literal de la LSC habremos de deducir que el fundador de la limitada no responde de la realidad de la aportación dineraria, salvo que entendiésemos que los fundadores son garantes solidarios de la fundación, en cuyo caso se pudiera aplicar el art. 30.1 LSC acerca de la responsabilidad de los fundadores. Con la previsión contenida en la Ley 14/2013, implícitamente, se llega a la conclusión de que sí deben acreditar la realidad de la aportación dineraria y que, de lo contrario, serían responsables, ya que los fundadores sólo se eximirían de acreditar esta realidad cuando se sometan voluntariamente a la responsabilidad solidaria por la realidad de tales aportaciones dinerarias. 


\section{Aportaciones no dinerarias}

En cuanto a la posible realización de aportaciones no dinerarias admite el art. 45.4 LC que las aportaciones sociales puedan consistir en bienes o derechos susceptibles de valoración económica si así es previsto por los estatutos o lo acuerda la asamblea general. Consecuentemente, se admite en la legislación cooperativa la realización de aportaciones no dinerarias, pero - a diferencia de lo estipulado para las sociedades de capital donde ambos tipos de aportaciones, dinerarias o no dinerarias, se desarrollan en un plano de igualdad- esta admisión sucede supeditada a previsión estatutaria o acuerdo de la asamblea general, es decir, frente a la aportación no dineraria el legislador mantiene una cierta desconfianza ya referida por la doctrina tradicional ${ }^{42}$. Pero esta opción no sólo es seguida por nuestra LC, sino que también distintas leyes autonómicas son partidarias de esta solución adoptada mayoritariamente: art. 57.3 LCPV; art. 58.5 LCG; art. 61.4 LCLR; art. 59.4 LCCyL; art. 69.4 LCIB; art. 64.5 LSCRM; art. 80.2 LCPA; art. 60.4 LCCant. En todo caso, como así ha sido apuntado por nuestra doctrina, podría haberse optado por la admisión de las aportaciones no dinerarias en igual grado que las dinerarias siguiendo el modelo, con buen criterio, establecido por nuestra LSC ${ }^{43}$. Este criterio, aunque para nosotros sería el óptimo, únicamente es atendido por el art. 55.4 LCCAT que sitúa en plano de igualdad tanto a la aportación dineraria como a la no dineraria. Por otra parte, el art. 76.1 LCCLM procede a la admisión de este tipo de aportaciones salvo que exista una prohibición estatutaria o un acuerdo de la asamblea en contrario. Por último, se situarían aquellas leyes autonómicas que prevén la posibilidad de existencia de las aportaciones no dinerarias supeditándolas al acuerdo favorable de la Asamblea General, sin exigir ningún otro requisito. Este es el caso del art. 49.5 LCCM; art. 54.4 LSCA que será la única disposición que aclare que la autorización puede ser conferida con carácter general sin que sea necesario que la asamblea proceda a la adopción de un acuerdo para cada caso, es decir, atendiendo igualmente a las aportaciones no dinerarias que se realicen en un momento posterior; art. 55.5 LCCV; y art. 65.4 LSCEX.

Al respecto de la admisión de las aportaciones no dinerarias, se ha planteado nuestra doctrina la posibilidad, una vez que ésta haya sido prevista legalmente, de que los estatutos pudiesen impedir que la

42 En este sentido, Vicent, Ley General..., 231.

43 En tal sentido, vid., Paniagua, La sociedad cooperativa..., 252. 
Asamblea general acuerde tales aportaciones concluyéndose que no cabe tal posibilidad ${ }^{44}$. También se ha planteado que, en la medida en que las leyes no contemplen esta previsión estatutaria, los estatutos pudieran admitir la realización de aportaciones no dinerarias considerándose, al respecto, que nada podría impedir esta posibilidad ${ }^{45}$.

Por otra parte, a tenor no sólo de nuestra LC, sino también de las distintas leyes autonómicas, hemos de concluir, en términos coincidentes con el régimen de las sociedades de capital, la exclusión de la aportación al capital del trabajo o de los servicios ${ }^{46}$.

En todo caso, en la escritura de constitución otorgada por los promotores debe expresarse, de existir aportaciones no dinerarias, la valoración y datos registrales de tales aportaciones a tenor del art. 10.1.e) LC. De esta forma, apreciamos, en la materia relativa a la valoración de estas aportaciones, una cierta similitud con el régimen establecido a tenor de las sociedades de capital, sociedad anónima (art. 67 a 72 LSC) y sociedad de responsabilidad limitada (art. 73 a 76 LSC) si bien, es cierto que existen diferencias significativas que seguidamente serán analizadas.

\subsection{VALORACIÓN}

No se puede obviar la predisposición, por razones evidentes, del aportante no dinerario a la sobrevaloración del objeto de su aportación, lo que comporta un incontestable riesgo para el resto de los aportantes, incluido el aportante dinerario interesado, como no puede ser de otro modo, en evitar que el aportante in natura reciba una participación superior a la que le correspondería. Igualmente, el acreedor social pudiera ver lesionada la expectativa de cobro de sus créditos, pues la sobrevaloración implica inflar artificialmente el capital nominal dotando a la sociedad de una apariencia de solvencia que no corresponde al capital real de la misma. Asimismo, el conocimiento de la valoración exacta del patrimonio social es esencial para la sociedad a quien interesará la sólida formación de su capital.

44 Torres, Régimen..., 59.

45 En este sentido, Morillas y Feliú, Curso..., 465, para quien no existen «inconvenientes a que los socios, por unanimidad, opten por esta forma de aportación en los estatutos, ya que se admiten que lo hagan en el seno de la asamblea, que funciona según el régimen de las mayorías».

46 Vid., como ejemplo, lo señalado por Rosalía Alfonso Sánchez et al., La Sociedad Cooperativa en la ley 27/1999, de 16 de julio, de Cooperativas (Granada: Comares, 2001), 97, para quien resulta destacable que nuestras leyes de cooperativas guarden silencio sobre la posibilidad de configurar tal aportación como prestaciones accesorias. 
Por consiguiente, la aportación in natura ha supuesto que se extremen las cautelas relativas no sólo a la realidad, sino también a la valoración de ésta ${ }^{47}$, valoración que si, en ocasiones, puede ser fácilmente determinada, en otros supuestos adolece de un alto grado de dificultad ${ }^{48}$.

\subsubsection{Introducción}

En este apartado se propone el estudio comparativo del distinto sistema de valoración de la aportación no dineraria en las sociedades de capital y en las sociedades cooperativas a fin de situarnos en un contexto que posibilite avanzar, a modo de conclusiones, hacia la emisión de una propuesta de regulación de la aportación al capital social en el marco de la sociedad cooperativa.

Así, para las sociedades de capital, la Ley exige que, tratándose de aportaciones no dinerarias en la sociedad anónima, éstas sean sometidas a valoración pericial mediante informe redactado por uno o varios expertos independientes designados por el Registrador mercantil. El informe, que se adjunta a la escritura de constitución de la sociedad o, en su caso, a la escritura de ejecución del acuerdo de aumento de capital, debe contener la descripción de la aportación, los datos registrales, si existieran, y la valoración de la aportación. El experto responde, salvo causa de exoneración, frente a la sociedad, frente a los accionistas y frente a los acreedores sociales, por los daños ocasionados por una errónea valoración de la aportación no dineraria prescribiendo, la acción de responsabilidad contra el experto, a los cuatro años de la fecha del informe. No obstante, se podría prescindir del informe pericial, art. 69 LSC, cuando la aportación no dineraria consista en valores mobiliarios que coticen en un mercado secundario oficial o en otro mercado regulado o en instrumentos del mercado monetario; cuando tratándose de bienes distintos a los referidos anteriormente, el valor razonable de los mismos se hubiera determinado, dentro de los seis meses anteriores a la fecha de la realización efectiva de la aportación, por experto independiente; cuando en la constitución de una nueva sociedad por fusión o escisión se haya elaborado un informe por experto independiente sobre el proyecto de fusión o escisión; cuando el aumento de capital social se realice con la finalidad de entregar nuevas acciones o participaciones sociales a los socios de la sociedad absorbida o escin-

47 Acerca de la necesidad de extremar las cautelas en este tipo de aportación, por todos, Garrigues, Tratado..., 867-868.

48 Como ejemplo, citaremos la aportación de bienes inmateriales. Sobre este particular, vid. Bercovitz, La aportación..., 165-196. 
dida y se hubiera elaborado un informe de experto independiente sobre el proyecto de fusión o escisión; y, por último, cuando el aumento del capital social se realice con la finalidad de entregar las nuevas acciones a los accionistas de la sociedad que sea objeto de una oferta pública de adquisición de acciones.

Si por la especialidad de la aportación no dineraria fuera posible que se prescindiera del informe pericial, los administradores deberán redactar un informe sustitutivo, art. 70 LSC, que debiera contener la descripción de la aportación, el valor de la aportación, el origen de esa valoración y, cuando proceda, el método seguido para determinarla sumándose a ello la certificación emitida por la sociedad rectora si la aportación hubiera consistido en valores mobiliarios cotizados en mercado secundario oficial o del mercado regulado del que se trate o en instrumentos del mercado monetario; una declaración en la que se precise si el valor obtenido corresponde, como mínimo, al número y al valor nominal y, en su caso, a la prima de emisión de las acciones emitidas como contrapartida; por último, una declaración en la que se indique que no han aparecido circunstancias nuevas que puedan afectar a la valoración inicial de la aportación no dineraria.

Ahora bien, en la sociedad anónima coexisten la exigencia de informe valorativo, y la consiguiente responsabilidad del experto independiente, y el especial régimen sancionador de la responsabilidad del fundador reforzándose, con ello, la solvencia de la sociedad anónima, ya que los fundadores sociales responderán solidariamente frente a la sociedad, los accionistas y los terceros de la realidad de las aportaciones sociales y de la valoración de las no dinerarias alcanzando, dicha responsabilidad, a las personas por cuya cuenta hayan obrado éstos.

Por su parte, en presencia de aportaciones no dinerarias a la sociedad de responsabilidad limitada, en los artículos 73 a 76 LSC se establece un sistema de responsabilidad solidaria, aplicable tanto a las aportaciones efectuadas en el momento fundacional como a las realizadas con motivo de una ampliación del capital social, en garantía no sólo de la realidad de las aportaciones no dinerarias, sino también de la valoración de éstas. Si para la sociedad anónima se exige, con carácter general, el sometimiento a valoración pericial de las aportaciones no dinerarias, tratándose de la sociedad de responsabilidad limitada se prescinde de un control externo, al menos obligatorio, de la valoración de tales aportaciones. Consecuentemente, arbitra un sistema de responsabilidad que afectará a los fundadores alcanzando igualmente a las personas por cuya cuenta hayan obrado éstos, personas que ostenten la condición de socios en el momento de acordarse el aumento de capital y quienes adquieran alguna participación desembolsada mediante 
aportaciones no dinerarias, que responderán solidariamente frente a la sociedad y los acreedores sociales de la realidad de dichas aportaciones y del valor que se les haya atribuido en la escritura. Igualmente, responderán de forma solidaria los administradores por la diferencia entre la valoración que hubiesen realizado en cumplimiento de lo dispuesto en el artículo 300 LSC, relativo al aumento de capital con aportaciones no dinerarias, y el valor real de las mismas. La responsabilidad de los fundadores alcanzará igualmente a las personas por cuya cuenta hayan obrado éstos. Ahora bien, los socios cuyas aportaciones no dinerarias sean sometidas a valoración pericial conforme a lo previsto para las sociedades anónimas quedan excluidos de la mencionada responsabilidad entendiendo que esta exclusión no sólo afecta al aportante, sino que también los restantes responsables se benefician de la misma incluido el administrador social.

Consecuentemente, en la sociedad de responsabilidad limitada, de existir informe valorativo de la aportación no dineraria, se excluye la responsabilidad que atañe no sólo a la valoración de tales aportaciones, sino también a la realidad de éstas, mientras que no se prevé responsabilidad alguna del fundador social.

Atendiendo a nuestro interés, régimen disciplinado para la sociedad cooperativa, en virtud del párrafo segundo del art. 45.4 LC, será el Consejo Rector quien deba determinar la valoración de las aportaciones in natura previo informe de uno o varios expertos independientes designados por este Consejo y, si así fuera establecido en los estatutos sociales, la valoración resultante deberá ser aprobada por la asamblea general. Si se tratara de una aportación no dineraria que suceda en ocasión al momento inicial o la fundación de la sociedad cooperativa, como así se dispone en el párrafo segundo del art. 45. 4 LC, el Consejo Rector, a posteriori, debiera revisar la valoración 49 .

Por otra parte, en la diversidad de regulaciones autonómicas interesa destacar la LCCLM, art. 76.4, que, para las aportaciones que tengan lugar con posterioridad a la constitución de la sociedad, encomienda la valoración al órgano de administración, mientras que, tratándose de aportaciones iniciales, distingue entre las que tengan lugar con anterioridad a la celebración de la asamblea constituyente, en cuyo caso la valoración será realizada por los fundadores o promotores, y las que tengan lugar con posterioridad a la celebración

49 Acerca de esta cuestión, Alfonso et al., La Sociedad..., 101; Paniagua, La sociedad cooperativa..., 253. 
de la asamblea constituyente y antes de la constitución de la sociedad, en cuyo caso la valoración debe ser realizada por las personas designadas como gestores.

Igualmente, la LSCA dispone, art. 54.4, que el régimen de valoración de las aportaciones no dinerarias se determinará reglamentariamente. En consecuencia, el art. 43 del Decreto 123/2014, de 2 de septiembre, por el que se aprueba el Reglamento de la Ley 14/2011, de 23 de diciembre de 2011, de Sociedades Cooperativas Andaluzas (en adelante, RLSCA), prevé en su apartado tercero que, cuando el procedimiento de constitución sea mediante asamblea constituyente, serán los promotores quienes deban valorar las aportaciones no dinerarias, salvo que se trate de aportaciones realizadas con posterioridad a la celebración de la Asamblea constituyente y antes de formalizar la constitución, en cuyo caso serán las personas gestoras quienes deban de proceder a valorarlas. Por otra parte, si las aportaciones se realizasen con posterioridad a la constitución, será encargado de este cometido el órgano de administración de la sociedad estableciéndose que, en ambos casos, procede la ratificación por la primera Asamblea General que se celebre tras la valoración.

\subsubsection{Informe del experto independiente}

El consejo rector debe hacer valer, a la hora de proceder a valorar las aportaciones no dinerarias, un informe previo de experto o expertos independientes. Ahora bien, en presencia de una aportación inicial serán los fundadores o promotores quienes deban proceder a la valoración de ésta, si bien, la introducción de un sistema diverso de valoración de las aportaciones en virtud del distinto momento en que tenga lugar su realización carece, a juicio de un sector de nuestra doctrina, de toda lógica, de manera que debiera exigirse igualmente que los fundadores nombren al experto o expertos independientes ${ }^{50}$. Por otra parte, como aquí se prefiere, será el consejo quien deba proceder al nombramiento del experto ${ }^{51}$. Si la responsabilidad por la valoración de las aportaciones no dinerarias contenida en el informe pericial re-

50 En el sentido señalado vid., Vicent, Ley General..., 236, para quien los expertos deben ser designados por los promotores de la fundación para el caso de las aportaciones iniciales o por el consejo rector en caso de aumento de capital; Paniagua, La sociedad cooperativa..., 253.

51 Así lo entienden, Torres, Régimen..., 71; Morillas y Feliú, Curso..., 466, quien sostiene, sobre la base de la valoración otorgada por el propio aportante, que, una vez constituido el consejo, será éste quien deba proceder al nombramiento del experto o expertos independientes. 
cae sobre el órgano de administración, es consecuente con el sistema arbitrado que la designación del experto o expertos independientes pese sobre él. Lo cierto es que, en el momento inicial de la sociedad, se produce una valoración que pudiera no ser definitiva, ya que a posteriori será ratificada o rechazada por el consejo rector de la cooperativa y, a su vez, cuando así lo dispongan los estatutos, posteriormente aprobada por la asamblea general.

Como así puede deducirse, las aportaciones fundacionales plantean el problema de la posible diferencia valorativa si, como aquí se prefiere, se mantiene que para este caso el nombramiento del experto corra a cargo del consejo pudiendo existir una discordancia entre el informe de los fundadores y el informe del experto ${ }^{52}$. Es más, incluso entendiendo que la designación del experto fuese responsabilidad de los fundadores, dado que el consejo, a posteriori, debe proceder a la revisión de la valoración, es lógico que para tener las garantías precisas a la hora de revisar la valoración inicial de estas aportaciones se hiciese asistir por un experto o expertos independientes ${ }^{53}$.

En todo caso, se debe tener en cuenta el carácter profesional del experto independiente, que debe manejar tanto los aspectos contables como los aspectos puramente valorativos de los bienes y derechos aportables cuya complejidad puede variar sustancialmente en función de las particularidades de lo aportado. Igualmente, se debe tener en cuenta que el interés de éste debe permanecer ajeno a los distintos intereses de los socios y de la sociedad. No olvidemos que con su intervención se está procurando, para la aportación no dineraria, un control externo, aunque el resultado pueda verse comprometido, ya que son los propios administradores quienes designan al experto independiente. Consecuentemente, consideramos que en caso de discrepancia entre el informe de los fundadores o promotores de la sociedad y el informe del experto independiente debiera prevalecer el informe del experto independiente salvando la posibilidad de acudir a la jurisdicción civil de cualquiera de los fundadores interesados.

En cuanto a la habilitación requerida debemos acudir al RRM, de manera que habrán de ser personas físicas o jurídicas que, a tenor del art. 340.1, pertenezcan «a profesión directamente relacionada con los bienes objeto de valoración o que se hallen específicamente dedi-

52 En este sentido, Torres, Régimen..., 71.

53 Esta cuestión estaría ciertamente determinada por el distinto alcance que se le confiere al informe del experto independiente en el sentido de excluir o no la responsabilidad del órgano de administración. 
cadas a valoraciones o peritaciones», es decir, que se trate de un profesional ${ }^{54}$ que tenga una suficiente formación y una adecuada experiencia ${ }^{55}$. Aluden expresamente al requisito de la necesaria habilitación legal el art. 55.4 LCCLM y el art. 49.5 LSCEX. Así, se deberá justificar las razones que han llevado a un determinado nombramiento, sea de un perito o de más, ya que, aunque nada se diga en nuestra LC, será preciso acudir al art. 340.2 RRM que dispone que «cuando los bienes a valorar sean de naturaleza heterogénea o, aun no siéndolo, se encuentren en circunscripción perteneciente a distintos Registros mercantiles, el Registrador podrá nombrar varios expertos, expresando en el nombramiento los bienes a valorar por cada uno de ellos». En consecuencia, serán «la heterogeneidad, la ubicación o la complejidad de los bienes» los que determinen la elección de uno o, en su caso, varios expertos independientes ${ }^{56}$.

Por otra parte, existen dos leyes autonómicas que confieren la posibilidad de que cualquier socio acuda a la jurisdicción civil, dentro de los cuatro meses siguientes a la valoración, para solicitar del juzgado ${ }^{57}$ o del árbitro ${ }^{58}$ el nombramiento de peritos a fin de revisar la valoración efectuada ${ }^{59}$. Ahora bien, que el juez o, en su caso, el árbitro pueda proceder a la designación del experto o expertos independientes merece una valoración negativa. Como así se afirma en el ámbito de las sociedades cooperativas, tal previsión, supone una «intromisión del legislador en las competencias propias del Estado» ${ }^{60}$. Por su parte, el art. 59.4 LCCyL dispone que la discrepancia entre el socio y el órgano que hubiera tomado la decisión respecto de la valoración de los bienes o derechos aportados por el socio podrá ser sometida a la jurisdicción civil. Esta previsión es, sin duda, superflua, ya que el socio disconforme

54 Reclaman la habilitación legal del experto para realizar la valoración de las aportaciones el art. 76.4 LCCLM y el art. 65.8 LSCEX.

55 Como expresamente señala Vicent, Ley General..., 236, ya que «no se han regulado reglamentariamente quiénes pueden ser expertos para tales avalúos, habrá que atender a cada una de las profesiones titulares (ingenieros, arquitectos, químicos, economistas, peritos tasadores de inmuebles y, en general, auditores de cuentas)».

56 En sentido, Morillas y Feliú, Curso..., 467.

57 Vid., en este sentido, el art. 65.8 LSCEX.

58 Así lo señala expresamente el art. 55.6 LCCV.

59 A tenor del art. 65.8 LSCEX, «El órgano judicial determinará cuál de las valoraciones realizadas se ajusta a la realidad, debiendo el o los socios o asociados aportantes completar la diferencia en efectivo, caso de que se determinase que la primera valoración fuera superior al precio real de los bienes o derechos aportados».

60 En este sentido, Torres, Régimen..., 71-72, que trae a colación la opinión sostenida por Morillas y Feliú, Curso..., 377 (ed. 2002). Igualmente, Pendón, «El capital...», 704. 
con cualquiera de las decisiones adoptadas por el órgano de administración siempre tiene abierta esta vía.

Respecto al contenido del informe se señala en el art. 45.4 LC que éste atañe a las características y el valor de la aportación y los criterios utilizados para calcularlo. Nuevamente será necesario acudir al ámbito propio de las sociedades anónimas, específicamente a los apartados 2 y 3 del art. 67 LSC $^{61}$. En nuestro ámbito particular de estudio, deberá figurar en el informe, de un lado, la descripción detallada de lo aportado, con sus datos registrales si existieran, aun cuando nada dice al respecto la LC62 que sólo habla de valoración ${ }^{63}$; de otro, los criterios de valoración utilizados.

Por otra parte, como así dispone expresamente la LCCLM en el art. 76.4, el informe del experto independiente se incorporará como anexo a la escritura de constitución de la sociedad o a la de ejecución del aumento del capital social, depositándose una copia autenticada en el registro de cooperativa competente al presentar a inscripción dicha escritura.

Cuando se pretende discernir acerca de la obligatoriedad del informe del experto, lo cierto es que en nuestra LC no se dice nada al respecto y de ello ha deducido nuestra doctrina que, tratándose de sociedades cooperativas, el silencio legal debe interpretarse como favorable al carácter vinculante del informe pericial y motivo suficiente para que se pueda exigir la responsabilidad de los administradores si éstos se apartan, sin una causa justa, de la valoración dada por el experto64. En consecuencia, cualquier socio podría reclamar al órgano de administración cuando éste se aparte de la valoración de los peritos, pese a que nuestra LC no diga que ambas valoraciones deban ser coincidentes. En todo caso, aplicaríamos, por analogía, el art. 67.3 LSC que establece que «El valor que se dé a la aportación

61 Vid., entre otros, María Angustias Díaz Gómez, Las aportaciones no dinerarias en la Sociedad Anónima: contenido, valoración y desembolso (Madrid: McGraw-Hill Interamericana de España, 1997), 247-258; Fernández, Aportaciones..., 261-275; Lojendio, «Aportaciones sociales (artículos 36...)», 90-100.

62 Interesa destacar que la exigencia de descripción consta en alguna de nuestras leyes autonómicas como la LSCEX en cuyo art. 65.7 se señala que «En la escritura de constitución, en la de ejecución del aumento del capital mínimo o en la que consten los sucesivos desembolsos deberán describirse las aportaciones no dinerarias con sus datos registrales si existieran, y la valoración en euros que se les atribuya».

63 En este sentido se manifiesta Vicent, Ley General..., 234.

64 En este sentido, Paniagua, La sociedad cooperativa..., 253-254; Torres, Régimen..., 72, para quien se habrá de estar al deber de diligencia, establecido legal o estatutariamente, aplicable a los administradores o miembros del Consejo rector. 
en la escritura social no podrá ser superior a la valoración realizada por los expertos» apartándose, de esta forma, del derogado art. 38 LSA (antes de la modificación operada por la Ley 3/2009, de 3 de abril sobre modificaciones estructurales de las Sociedades mercantiles), de manera que ya no será aplicable la discrepancia valorativa tolerada por RRM, ya que, en virtud del párrafo segundo del artículo 133.2 RRM, procede la inscripción de la sociedad por el Registrador mercantil cuando el valor escriturado de las aportaciones in natura no supere el veinte por ciento del valor referido por el experto independiente. Consecuentemente, el Registrador Mercantil debe negar la inscripción de la sociedad cuando el valor escriturado supere a la valoración realizada por los expertos.

En el tema relativo al pago de los honorarios del experto independiente, nuevamente, distinguiremos entre aquellos supuestos en los que el nombramiento del mismo deba de hacerse por imposición expresa de la ley, en cuyo caso siempre deberá la sociedad cooperativa soportar el pago de los mismos, mientras que en aquellos casos en los que el nombramiento sea discrecional, será el socio demandante de sus servicios quien debiera soportar los gastos que ocasione dicho nombramiento.

\subsubsection{Responsabilidad solidaria de los miembros del Consejo Rector}

A tenor del art. 45.4 LC responden solidariamente los consejeros de la realidad de dichas aportaciones y del valor que se les haya atribuido. Está responsabilidad está sometida al límite temporal de los cinco años. No obstante, la Ley no aclara a partir de qué momento debe computarse el plazo de los cinco años por lo que nuevamente habrá que diferenciar entre las aportaciones no dinerarias que tengan lugar en el momento fundacional de la sociedad y las aportaciones no dinerarias que sucedan en un momento posterior de la sociedad. Para las primeras de ellas se habrá de estar al momento constitutivo de la sociedad, mientras que para las segundas se atenderá al desembolso por parte del aportante 65 .

65 Como así se sostiene por Paniagua, La sociedad cooperativa..., 254, el artículo en cuestión no aclara si el cómputo del plazo comienza desde la valoración por el Consejo de las aportaciones no dinerarias o desde el desembolso por el aportante. El autor se inclina, opinión aquí mantenida igualmente, por esta segunda opción. En todo caso, se estará refiriendo a las aportaciones no iniciales de la sociedad.

También la LCCAT en su art. 70.5 prevé que la acción de responsabilidad prescribirá a los cinco años desde el momento en que se hubiera realizado la aportación. 
Por otra parte, la atribución de responsabilidad a los consejeros es la opción seguida mayoritariamente por las distintas leyes autonómicas, si bien, existen ciertas particularidades en leyes como la LCCM cuando dispone en su art. 49.6 que los administradores que sometan la valoración de las aportaciones no dinerarias a informe de experto independiente quedan exentos de responsabilidad, o bien, la LCCAT que en su artículo 70.5 prevé que el consejo rector quede exento de responsabilidad si somete la valoración de las aportaciones no dinerarias a informe de una persona experta independiente. También el RLSCA cuando en el párrafo quinto del art. 43.3 dispone: "De la existencia y valoración de dichas aportaciones responderán solidariamente quienes las hayan realizado. Tanto las personas promotoras o las personas gestoras, en su caso, como el órgano de administración podrán solicitar el informe de una o varias personas expertas independientes, bajo su responsabilidad, en cuyo caso quedarán exentos de responsabilidad siempre y cuando no se aparten de la valoración realizada en dicho informe, que versará, como mínimo, sobre las características de la aportación, su valor y criterios utilizados para obtenerlo», es decir, la exención de responsabilidad no procedería si se apartasen de lo estipulado en el informe o cuando éste no contuviese las exigencias mínimas para proceder a la valoración de las aportaciones no dinerarias. En análogos términos, la LCCV prevé la exención de responsabilidad de los miembros del consejo rector cuando sometan su valoración a informe de experto independiente ${ }^{66}$. A semejante solución parece que llega el art. 80.2 LCPA cuando obliga a que, en presencia de aportaciones no dinerarias, el órgano de administración designe a uno o varios expertos independientes «con el objeto de que éstos, bajo su responsabilidad, determinen justificadamente el valor de la aportación no dineraria, previa descripción de las características de los bienes e indicación de los criterios utilizados para calcular su valor». Sin embargo, la LCCLM dispone algo diametralmente opuesto, ya que de forma expresa prevé que la responsabilidad de los administradores, así como de los socios fundadores o promotores de la cooperativa respecto de las aportaciones iniciales suceda con independencia de la existencia o no de informe previo de los expertos independientes ${ }^{67}$.

66 A este respecto, art. 55.6 LCCV.

67 Vid., el párrafo uno del art. 76.5 LCCLM cuando establece: «En todo caso, las personas integrantes del órgano de administración, así como los socios/as, fundadores/ as o promotores/as de la cooperativa respecto de las aportaciones iniciales, responderán solidariamente frente a la cooperativa y frente a los acreedores sociales de la realidad de las aportaciones sociales al capital social, así como, especialmente, del valor que 
En cuanto a la legitimación pasiva, los consejeros, pero también los aportantes, fundadores o promotores o incluso los gestores -tal y como señala la LCCLM que distingue, según se refirió en su momento, entre las aportaciones no dinerarias que tengan lugar con anterioridad a la celebración de la asamblea constituyente, en cuyo caso la valoración será realizada por los fundadores o promotores, y las que tengan lugar con posterioridad a la celebración de la asamblea constituyente y antes de la constitución de la sociedad, en cuyo caso la valoración debe ser realizada por las personas designadas como gestores- serán responsables de la valoración de las aportaciones no dinerarias. También, así lo disponen expresamente varias de nuestras leyes autonómicas como el art. 57.3 LCPV; el art. 80.2 LCPA; o el art. 60.4 LCCant, será responsable el experto independiente que actúa bajo su responsabilidad.

En cuanto a los legitimados activamente para el ejercicio de la acción contra los administradores, el artículo 45.4 LC no concreta nada al respecto. Por su parte, el art. 49.6 LCCM atribuye responsabilidad solidaria frente a la cooperativa y frente a los acreedores sociales de la realidad de las aportaciones y del valor atribuido a las aportaciones no dinerarias atribuyendo esta legitimación activa a cualquier acreedor en caso de insolvencia de la cooperativa. En términos, más o menos, coincidentes se pronuncia el art. 55.6 LCCV. El art. 76.5 LCCLM atribuye responsabilidad frente a la cooperativa y frente a los acreedores sociales añadiendo expresamente que se trata de una responsabilidad solidaria.

Como los distintos sujetos responsables son garantes solidarios ex lege del equilibrio entre capital y patrimonio, el objeto de la responsabilidad de éstos se circunscribe a la reintegración en el patrimonio social de las aportaciones ficticias o sobrevaloradas. En todo caso, la disciplina a la que ha de ajustarse la responsabilidad por aportaciones no dinerarias es la de la solidaridad pasiva (arts. 137 y ss. CC), cuyo efecto más destacado es la posibilidad que asiste al acreedor de reclamar de cada socio el cumplimiento íntegro de la deuda. Producida cualquiera de las circunstancias desencadenantes de la sanción, aportaciones no dinerarias ficticias o sobrevaloradas, el acreedor podrá dirigir la acción contra cualquiera de los legitimados pasivamente o contra todos simultáneamente.

se les haya atribuido a las no dinerarias, sin perjuicio de la existencia o no de informe previo de una o varias personas expertas independientes en la forma indicada en este artículo». 


\subsubsection{Ratificación por la Asamblea General}

A tenor de lo señalado en el párrafo primero del art. 45.4 LC, si los estatutos así lo disponen, la valoración dada por el consejo rector deberá ser aprobada por la Asamblea general. Son varias las opciones que esta ratificación suscita, ya que podría «condicionarse a la expresa previsión estatutaria; ser un requisito directamente exigido por la norma; o bien, depender de la actuación de cualquier socio o grupo de socios» ${ }^{68}$.

Ciertamente, podría existir una previsión estatutaria al respecto como, de esta forma, se prevé en la propia LC, opción seguida mayoritariamente por las distintas leyes autonómicas de cooperativas, art. 57.3 LCPV; art. 61.4 LCLR; art. 69.4 LCIB; art. 64.5 LSCRM; art. 76.4 LCCLM; art. 80. 2 LCPA; art. 60. 4 LCCant; art. 59. 4 LCCyL que añade, aunque tal previsión no fuese necesaria, que la discrepancia que exista entre el socio y el órgano que hubiera tomado la decisión respecto de la valoración de los bienes o derechos aportados por el socio podrá ser sometida a la jurisdicción civil.

También se pudiera someter, la exigencia de ratificación de la asamblea general, a un posterior requisito adicional y no sólo al acuerdo estatutario. Este es el caso del art. 65.8 LSCEX que tras señalar que, si los estatutos así lo prevén, la valoración debe ser aprobada por la asamblea general que someterá a votación la valoración efectuada a petición del órgano de administración o de un tercio de los socios o asociados. A ello se suma que cualquier socio o asociado, dentro de los cuatro meses siguientes a la valoración, podrá solicitar de la jurisdicción correspondiente y a su costa, el nombramiento de expertos independientes para revisar la valoración efectuada. El juez determinará cuál de las valoraciones realizadas se ajusta a la realidad, debiendo el socio o los socios o asociados aportantes completar la diferencia en efectivo, si es que la primera valoración fuese superior al valor real. También se condiciona la ratificación por la asamblea a la solicitud del socio en el art. 48.2 LCAR donde, tras señalar que los estatutos pueden establecer los supuestos en que sea exigible la valoración por expertos independientes, dispone que, en todo caso, la valoración podrá ser revisada por acuerdo de la asamblea general, a petición de cualquier socio, en el plazo de un mes desde que se conociese.

Por otra parte, el art. 49.6 LCCM exige que la valoración sea ratificada por la asamblea sin que exista una previsión estatutaria que así

68 Así es señalado expresamente por Torres, Régimen..., 74. 
lo disponga; en análogos términos, el RLSCA dispone, en su art. 43.3, que la «valoración realizada por las personas gestoras, en el procedimiento de constitución, o por el órgano de administración deberá ser ratificada por la primera Asamblea General que se celebre tras la valoración», es decir, que una vez valoradas las aportaciones no dinerarias, dicha valoración sea ratificada por la asamblea general. En cuanto al art. 55.6 LCCV, tampoco exige previsión estatutaria al respecto disponiendo que, dentro de los cuatro meses siguientes a la valoración efectuada por el consejo rector, cualquier socio, a su costa, puede solicitar del árbitro o del juzgado competente el nombramiento de un experto independiente para que éste revise la valoración efectuada. Será el árbitro o el juzgado competente quien deba decidir si esa valoración es justa, de manera que, ante la sobrevaloración de lo aportado, el socio aportante debe completar en efectivo esa valoración.

En todo caso, que tanto la LSCEX como la LCCV prevean la posibilidad de acudir al ámbito jurisdiccional para proceder al nombramiento de experto independiente es, sin duda, un exceso ${ }^{69}$.

No dice nada al respecto de una posterior ratificación por la asamblea general de la sociedad cooperativa la LCCAT lo que, a nuestro juicio, merece una valoración positiva, puesto que entendemos que con el requisito de la ulterior ratificación se suma un control más a la valoración de las aportaciones no dinerarias que tiene como resultado un régimen excesivamente garantista revelador de la visión que el legislador tiene acerca de tales aportaciones y de la posibilidad de que éstas sean sobrevaloradas. Tampoco prevé ratificación alguna por la asamblea la LCG o la LCFN.

Ahora bien, lo que no parece suscitar duda alguna es que la posterior ratificación de la valoración atribuida a la aportación no dineraria no desplaza la responsabilidad de los administradores o de los fundadores en el momento constitutivo de la sociedad 70 . A este respecto, la LCCLM (art. 76.4) señala expresamente que, en caso de que así esté previsto en los estatutos, la valoración de las aportaciones deberá ser aprobada previamente o, en su caso, ratificada por la primera asamblea que se celebre tras la valoración atribuida por el órgano de administra-

69 Vid. supra, apartado 2.1.2., relativo al informe previo del experto independiente.

70 En este sentido, Paniagua, La sociedad cooperativa..., 254; Torres, Régimen..., 74. Para ambos autores la razón que subyace a la atribución de responsabilidad a los consejeros, pese a existir una ratificación de la valoración por parte de la asamblea, es que el interés protegido no responde únicamente ni a la sociedad ni a los socios, sino que también está en juego el interés del acreedor social. 
ción, que, en todo caso, no libera al órgano de la responsabilidad por la infravaloración o la sobrevaloración de la aportación no dineraria.

\subsubsection{Justificación del sistema de valoración de las aportaciones no dinerarias}

Tal y como dispone la LC — sin tener en cuenta la pluralidad de opciones, más o menos coincidentes con ésta, seguidas por las distintas leyes de cooperativas autonómicas - previstas las aportaciones no dinerarias por los estatutos o acordadas por la asamblea general, el consejo rector fijará su valoración, previo informe del experto independiente, respondiendo solidariamente los consejeros durante cinco años de la realidad de dichas aportaciones y del valor de éstas. Por otra parte, la valoración atribuida por el consejo rector a tales aportaciones no dinerarias, si los estatutos así lo prevén, debe ser aprobada por la asamblea general. En cuanto a las aportaciones iniciales, una vez constituido el consejo rector, tendrá que ratificar la valoración de éstas.

Todo este complejo sistema de valoración de las aportaciones no dinerarias es, para un sector de nuestra doctrina, un medio de evitar «la tentación que suponía acudir a la compra de los bienes en lugar de recibirlos en concepto de aportación social con el peligro de sobrevaloración de los bienes» ${ }^{71}$. Ello es así por la falta para la sociedad cooperativa ${ }^{72}$, como así también ocurre respecto de la sociedad de responsabilidad limitada, de un precepto paralelo al art. 72 LSC aplicable a la sociedad anónima. Así, con el fin de evitar el fraude consistente en que se eluda el régimen de la aportación no dineraria, aportando dinero y vendiendo después a la sociedad lo que verdaderamente se pretendía aportar, las adquisiciones de bienes a título oneroso realizadas por la sociedad anónima desde el otorgamiento de la escritura de constitución o de transformación en este tipo social y hasta dos años de su inscripción en el Registro Mercantil, al margen de que deban ser aprobadas por la junta general si su importe fuese, al menos, de la décima parte del capital social — capital suscrito y no desembolsado—, habrán de ser objeto de informe elaborado por los administradores que justifique la adquisición y de informe valorativo por experto independiente, salvo que se trate de adquisiciones comprendidas en las operaciones ordinarias de la sociedad o que se verifiquen en mercado secundario oficial o en subasta pública.

71 Así lo entiende a Alfonso et al., La Sociedad..., 101.

72 Denunciaba ya esta carencia Vicent, Ley General..., 237. En análogos términos, Alfonso et al., La Sociedad..., 101; Paniagua, La sociedad cooperativa..., 254. 
Ahora bien, a falta de una regulación expresa de la aportación no dineraria encubierta, se aplicarán las técnicas generales para el control de ésta como el fraude de Ley o fraude de terceros. Esta solución es, para nosotros, garantía suficiente, dado que la sociedad cooperativa debe contar, por las características definitorias de su propia tipo, con un régimen más flexible que el arbitrado a tenor de las sociedades anónimas $^{73}$.

\subsection{SUPUESTOS ESPECIALES DE RESPONSABILIDAD POR APORTACIONES NO DINERARIAS: ENTREGA, SANEAMIENTO Y TRANSMISIÓN DE RIESGOS}

El art. 45.4 LC remite, en cuanto a la entrega, saneamiento y transmisión de riesgos frente a las aportaciones no dinerarias, a lo dispuesto en el antiguo art. 39 LSA, en la actualidad arts. 63 a 66 LSC. Algunas leyes autonómicas optan por la misma solución que la LC, siendo esta la opción preferida, como es el caso del art. 49.5 LCCM; art. 59.4 LCCyL; art. 64.5 LSCRM; art. 76.5 LCCLM; art. 80.2 LCPA; y art. 60.4 LCCant que nos reenvía ya a la actual LSC. Otras prefieren realizar una exposición del régimen normativo aplicable. Sería el supuesto de la RLSCA y LCCEX que en los arts. 43.2 y 65.7, respectivamente, se refieren, de forma expresa, a la transmisión de bienes muebles o inmuebles, o derechos asimilados a ellos, a la aportación de un derecho de crédito y a la aportación de una empresa o establecimiento. Por otra parte, algunas de las leyes autonómicas no se hacen eco de tal cuestión, sería el caso de la LCPV, LCG, LCLR, LFCN y LCAR.

Una posición singular encontramos en la LCIB, art. 69.4, que se limita a atender a la aportación de derechos declarando que el socio responde de su legitimidad y de la solvencia del deudor si se trata de un crédito; igualmente en la LCCV, art. 55.5, se declara que la entrega y saneamiento de estas aportaciones no dinerarias se regirá por lo establecido en la legislación que le sea aplicable y, en consecuencia, no regula el supuesto de la transmisión de los riesgos; también encontramos una singularidad en la LCCAT, art. 70.5, que se remite únicamente al art. 64 LSC, de manera que sólo se refiere a la obligación de entrega, saneamiento y transmisión de riesgos si la aportación consistiera en bienes muebles o inmuebles o derechos asimilados a ellos.

73 Téngase presente también las razones de orden práctico que hacen que, a tenor del Real Decreto Legislativo 1/1993, de 24 de septiembre, por el que se aprueba la Ley del Impuesto sobre Transmisiones Patrimoniales y Actos Jurídicos Documentados, la cuestión impositiva motive que sea más ventajosa la realización de aportaciones que de adquisiciones onerosas. 
En todo caso, circunscribiendo las obligaciones de entrega y saneamiento y la transmisión de créditos, como obligaciones contractuales del aportante establecidas en los art. 64 a 66 LSC, se atiende, sin ánimo de agotar los posibles objetos de aportación social, a la aportación de bienes muebles o inmuebles o derechos asimilados a ellos, aportación de un derecho de crédito y aportación de una empresa o establecimiento.

\subsubsection{Aportación de bienes muebles o inmuebles o derechos asimilados}

A este respecto, procederemos a diferenciar entre la aportación realizada a título de propiedad y la aportación realizada a título de uso.

Así, tratándose de una aportación realizada a título de propiedad, la sociedad adquiere la titularidad plena del bien o derecho aportado sucediendo la desvinculación definitiva del aportante respecto del objeto de su aportación. El artículo 60 LSC establece una presunción iuris tantum en favor del título de propiedad, de manera que, salvo expresa estipulación en contra, toda aportación se considera así realizada. En cuanto al régimen jurídico de la aportación a título de propiedad acudiremos, en virtud de los artículos 1681.2 CC y 64 LSC, a la normativa característica de la compraventa que será de aplicación por analogía ${ }^{74}$.

De esta forma, en virtud del artículo 64 LSC, el aportante de bienes muebles o inmuebles o derechos asimilados a ellos estará obligado a la entrega en los términos establecidos en el CC para el contrato de compraventa. Así, acudiremos a los artículos 1462 a 1473 CC, con excepción de los artículos 1466 y 1476, relativos al precio y, por lo tanto, no susceptibles de traslación al ámbito societario. La entrega significa la transmisión definitiva, en nuestro caso, de lo aportado. Junto a la entrega real que tiene lugar cuando la cosa o derecho se ponga en poder y posesión del comprador, en nuestro caso de la sociedad, el artículo 1462.2 CC facilita la tradición instrumental, ya que el otorgamiento de la escritura pública equivale a la entrega salvo que de aquélla no resultare o se dedujere claramente lo contrario. La tradición instrumental, que es una de las variantes de la traditio

74 Vid., en este sentido, Girón, Derechos de sociedades..., 220, para quien «el tratamiento de las cuestiones relativas a la aportación en propiedad (transmisión, riesgos, evicción) mediante las normas de la compraventa, es simplemente analógica. No se trata de compraventa, sino del contenido del contrato plurilateral de organización, que es el social, en el que la conformación del patrimonio permite esa analogía». 
ficta que conoce nuestro Derecho, no significa eliminar el requisito de la tradición, sino que representa una de las formas posibles de efectuar la entrega. De esta forma, ante la imposibilidad de entrega real, el otorgamiento de la escritura no puede equivaler a dicha entrega o bien la traditio será nula sin que se pueda verificar cesión alguna de dominio a la sociedad75.

Por otra parte, el aportante se halla obligado al saneamiento en los términos establecidos en el CC para el contrato de compraventa, artículos 1474 a 1499 sobre responsabilidad del vendedor frente al comprador por la posesión legal y pacífica de la cosa vendida y por los defectos ocultos que ésta tuviere. Por lo tanto, la obligación de saneamiento comprende dos supuestos diversos. De un lado, el saneamiento por evicción; de otro, el saneamiento por vicios o defectos ocultos de la cosa aportada.

En el supuesto de evicción, el aportante se verá obligado a la restitución de las participaciones asumidas por el valor nominal que tuviere lo aportado al tiempo de la evicción —valor que puede ser superior, igual o inferior al atribuido originariamente a la aportación-, los rendimientos de ésta en el caso de que la sociedad hubiese sido condenada en juicio a su restitución, la cantidad proporcional de gastos deducidos de la escritura de constitución y los daños e intereses si aportó de mala fe. Por su parte, tratándose de una responsabilidad por vicios o defectos ocultos, si la sociedad opta por la rescisión del negocio de la aportación, el aportante deberá restituir las participaciones recibidas a cambio de su aportación y abonar una cantidad proporcional de los gastos de escritura y los daños e intereses si aportó de mala fe; por el contrario, si optase por la reducción del precio, la restitución ha de ser en proporción a la disminución del valor de lo aportado a juicio de peritos.

De lo señalado, podemos inferir que mientras el saneamiento por evicción supone anular el negocio de la aportación desde el momento en que la evicción tuviese lugar, el saneamiento por vicios o defectos ocultos viene referido al momento fundacional.

En cuanto a la transmisión de riesgos, el art. 64 LSC declara aplicable el régimen establecido en el CCom sobre el contrato de compra-

75 A este propósito, vid. Francisco Vicent Chuliá, Compendio crítico de Derecho Mercantil, I (Barcelona: J. M. Bosch, 1991), 440; Manuel de la Cámara Álvarez, El capital social en la sociedad anónima, su aumento y disminución (Madrid: Consejo General del Notariado, 1996), 88-90; Fernández, Aportaciones..., 103-107; Lojendio, «Aportaciones sociales (artículos 18...)», 563-564; Rubio, La aportación..., 126-127. 
venta. Por riesgo en la aportación hemos de entender la posibilidad de que el objeto aportado se pierda o deteriore sin que medie culpa alguna del aportante. Por otra parte, es necesario señalar que el vendedor o, en nuestro caso, el aportante soporta el riesgo, por regla general, hasta la puesta a disposición del adquirente ${ }^{76}$.

La aportación de bienes muebles o inmuebles o derechos asimilados a título de uso significa única y exclusivamente la cesión del derecho de goce, sin que exista desvinculación jurídica del aportante que guarda la facultad de recuperar el uso temporalmente cedido a la sociedad $^{77}$. En este caso, serán de aplicación analógica, las normas relativas al contrato de arrendamiento ${ }^{78}$, ya que con esta aportación sólo se transmite a la sociedad el uso del bien resultando preciso, para ello, la colaboración del socio que asumirá, como aportante, la obligación de posibilitar el uso y disfrute del bien por la sociedad durante el tiempo señalado. De ahí su proximidad con el contrato de arrendamiento y la aplicación analógica de los arts. 1542 a 1574 CC.

En cuanto a las especialidades de este título de aportación, destaca el art. 1553 CC que, en materia de saneamiento remite, a su vez, a la normativa sobre compraventa. Por consiguiente, en una primera aproximación, se pudiera entender que el régimen aplicable será el mismo que el de la aportación en propiedad; sin embargo, a las obligaciones que incumben al aportante, en virtud del saneamiento de las aportaciones a título de propiedad, deberán sumarse todas aquéllas que resulten de la aportación a título de uso y que se materializan, según se ha señalado, en las obligaciones propias del arrendador en el contrato de arrendamiento. Así, el aportante a título de uso no sólo deberá cumplir con las garantías previstas para la compraventa, sino que también está obligado a mantener al arrendatario (sociedad) en el goce pacífico de lo arrendado (aportación) durante el tiempo de duración del contrato, art. 1554.3 CC. Asimismo, deberá realizar todas las reparaciones necesarias a fin de conservar la cosa en estado de servir para el uso a que ha sido destinada, art. 1554.2 CC.

76 Sobre la transmisión del riesgo, vid. Mariano Alonso Pérez, El riesgo en el contrato de compraventa (Madrid: Montecorvo, 1972); Cámara, El capital..., 156-158; Fernández, Aportaciones..., 111-113.

77 Vid., acerca de la naturaleza jurídica de la aportación a título de uso, especialmente, José Javier López Jacoiste, El arrendamiento como aportación del socio, Ed. Uni. Navarra, Pamplona, 1955, p. 78.

78 Vid., a este respecto, López, El arrendamiento..., 104-105; Lojendio, «Aportaciones sociales (artículos 36...)», 53-54; Fernández, Aportaciones..., 116-117; Bercovitz, La aportación..., 220-221; Rubio, La aportación..., 140-142. 


\subsubsection{Aportación de un derecho de crédito}

Teniendo presente que el contenido del derecho de crédito puede referirse no sólo al crédito dinerario, sino que igualmente podrá comprender otros bienes de diversa naturaleza79, en virtud del artículo 65 LSC «si la aportación consistiere en un derecho de crédito, el aportante responderá de la legitimidad de éste y de la solvencia del deudor».

Se trata de una norma imperativa, estrechamente vinculada al principio de efectividad del capital social, donde el legislador se aparta del régimen general de la transmisión de créditos según el cual el cedente, salvo pacto en contra, no responde de la solvencia del deudor. De tal forma, el régimen contenido en el artículo 65 LSC difiere tanto del CC, artículo 1529, como del CCom, artículo 348, pues el aportante no sólo responde de la legitimidad del crédito, nomen verum, sino también de la solvencia del deudor, nomen bonus ${ }^{80}$. Ello obedece a la intención consciente del legislador de garantizar la correspondencia entre el capital y el patrimonio ${ }^{81}$.

La transmisión del crédito a la sociedad se entiende efectiva desde la fecha del otorgamiento de la escritura, momento en el que el socio asume la responsabilidad prevista en el artículo 65 LSC 82 , cuestión estrechamente relacionada con la obligada notificación de la aportación del crédito al deudor, obligación que pesa sobre la sociedad, en concreto sobre los administradores de ésta ${ }^{83}$, si bien, la validez de la aportación no depende, en última instancia, de dicha notificación. Consecuentemente, en ausencia de notificación alguna, el deudor podría liberarse de su obligación pagando al aportante, pese a que, ante la inexistencia de tal notificación, si el deudor conocía la cesión del crédito, el pago hecho al aportante perdería el efecto liberatorio. En todo caso, si el pago es correcto, el aportante deberá reintegrar a la sociedad el importe de lo percibido en concepto de pago. La carga de la prueba recae sobre la sociedad.

79 En este sentido, vid., entre otros, Fernández, Aportaciones..., 177; Lojendio, «Aportaciones sociales (artículos 36...)», 38.

80 Ya con anterioridad a la Ley de 1951, la doctrina se pronunciaba en contra de la aplicación del régimen general de la transmisión de créditos a la aportación social, pues se consideraba que, de lo contrario, el aportante no contribuiría, adecuadamente, a la formación del patrimonio social, vid., en este sentido, Garrigues, Tratado..., 445.

81 Vid., sobre este particular, Girón, Derecho de Sociedades..., 222.

82 En este sentido, entre otros, Lojendio, «Aportaciones sociales (artículos 18...)», 568.

83 Sobre este particular, Cámara, El capital..., 104-105. 
En cuanto al límite de la responsabilidad del aportante por la solvencia del deudor parece claro que el aportante no responderá de la solvencia futura del deudor, sino que la exigencia de íntegra cobertura del capital social determina que el momento decisivo sea el desembolso de la aportación social. Que el aportante no haya de responder de la solvencia futura del deudor se justifica, según doctrina en la materia, de un lado, en el hecho indiscutible de que todo acreedor, originario o derivativo debe asumir el riesgo de que el deudor, solvente en principio, devenga posteriormente en insolvente; de otro, si el aportante debiera responder indefinidamente de la solvencia del deudor sería, en realidad, un fiador y la fianza no se presume.

\subsubsection{Aportación de empresa o establecimiento}

Tratándose de la aportación de empresa, y con anterioridad a la reforma de la sociedad anónima de 1989, resultaba preciso acudir al artículo 1532 CC, según el cual el aportante respondería de la legitimidad del todo en general, pero no estaba obligado al saneamiento de cada una de las partes de la empresa, salvo el caso de evicción del todo o de la mayor parte. El precepto mencionado fue objeto de críticas contundentes, pues sólo atendía al aspecto cuantitativo cuando hubiera sido preferible contar también con el aspecto cualitativo. A tenor de las críticas recibidas, en la antigua Ley de Sociedades Anónimas de 1989 se modifica este criterio eliminando la remisión expresa al citado precepto y ampliando el régimen de responsabilidad del aportante.

En la actualidad acudiremos al art. 66 LSC, de manera que la obligación de saneamiento comprende el conjunto de la empresa, si el vicio afecta a la totalidad o a alguno de los elementos esenciales, pero también existe obligación de sanear los elementos de la empresa que sean de importancia por su valor patrimonial. Por lo tanto, del tenor literal del referido precepto colegimos la existencia de una obligación relativa al saneamiento pleno y otra relativa al saneamiento individualizado.

A su vez, el saneamiento del conjunto de la empresa comprende dos supuestos diversos: de un lado, el vicio o la evicción que afecte a la totalidad; de otro, el vicio o la evicción que afecte a alguno de los elementos esenciales para la normal explotación de la empresa.

La posibilidad de que el vicio o la evicción afecten a la totalidad de la empresa constituye un supuesto de difícil verificación en la práctica reconduciendo, en todo caso, el vicio o la evicción, no a cada uno de los elementos integrantes de la empresa, sino a la empresa concebida globalmente. Más factible será, por el contrario, que el vicio o la 
evicción afecten a un elemento esencial de la empresa. De esta forma, cuando el saneamiento del conjunto de la empresa tenga lugar como consecuencia de la evicción de un elemento esencial de la empresa, el comprador puede optar entre la previsión contenida en el artículo 1478 CC en virtud del cual podrá reclamar del vendedor, en nuestro caso del aportante, el valor del objeto perdido más una serie de conceptos referidos en el citado precepto, o bien podrá reclamar, en su caso, la resolución del contrato, pero con la obligación de devolver la cosa sin más gravámenes que los que tuviera al adquirirla, de conformidad con el artículo 1479 CC.

Que se rescinda el negocio de la aportación implica, a su vez, la anulación de las participaciones suscritas por el aportante mediante la restitución de lo aportado y ello significa, invariablemente, reducir el capital social para lo cual se habrán de respetar las garantías arbitradas al efecto en la LSC.

Por su parte, cuando el saneamiento del conjunto de la empresa tenga lugar como consecuencia de la existencia de un vicio oculto que afecte a un elemento esencial de la empresa se plantea la posibilidad de optar entre el ejercicio de la acción redhibitoria o de la acción quanti minoris, ex artículo 1486 CC. En consecuencia, se podría decidir, respectivamente, o la resolución del contrato o la reducción del precio de lo aportado. En el primero de los casos señalados procede la devolución de lo aportado, la anulación de las participaciones suscritas y la reducción del capital social. En el segundo procede, a su vez, la reducción del valor del bien aportado, la anulación de las participaciones correspondientes a la diferencia y la reducción proporcional del capital social.

En cuanto al saneamiento individualizado de aquellos elementos de la empresa que "sean de importancia por su valor patrimonial», será preciso señalar que, tratándose de la evicción de un elemento integrante de la empresa no será posible, en ningún caso, que se aplique la solución establecida en el artículo 1479 CC, pues si el elemento afectado por la evicción no es esencial, no cabe aplicación alguna de la presunción que se contiene en el referido artículo ${ }^{84}$. Consecuentemente, acudiríamos a lo dispuesto en el artículo 1478 CC. Por su parte, si el saneamiento individualizado tuviese lugar en función de la existencia de un vicio oculto que afectase a un elemento no esencial, pero de importancia por su valor patrimonial, se podría optar, artículo 1486 CC, entre la resolución de la aportación o la reducción del precio de lo aportado.

84 Vid. Cámara, El capital..., 154-155. 


\subsection{Continuidad de la cooperativa en la titularidad Del Bien O DERECHO APORTADO}

A tenor del art. 45.5 LC «Las aportaciones no dinerarias no producen cesión o traspaso ni aun a los efectos de la Ley de Arrendamientos Urbanos o Rústicos, sino que la sociedad cooperativa es continuadora en la titularidad del bien o derecho. Lo mismo se entenderá respecto a los nombres comerciales, marcas, patentes y cualesquiera otros títulos que constituyesen aportaciones a capital social»85.

Así pues, distinguiríamos dos supuestos diversos. De un lado, el derecho de arrendamiento; de otro, los derechos de uso que se harían efectivos sobre bienes inmateriales ${ }^{86}$.

En cuanto al arrendamiento, si lo que se aportara fuese un bien inmueble, no se produciría la cesión o traspaso a los efectos de la Ley de Arrendamientos Urbanos (en adelante, LAU) o Rústicos (LAR), sino que la titularidad de dicho bien seguirá en manos de la sociedad cooperativa lo que significa la previsión de un régimen más benigno que el estipulado para otras sociedades, de forma que la cooperativa continúa siendo la titular del bien o derecho o, como así se ha destacado por nuestra doctrina, «en forma más técnica, establece la cesión legal del contrato» ${ }^{87}$.

Los efectos deducidos de ello son varios. Así, por ejemplo, no será de aplicación lo dispuesto en el art. 8 LAU que exige, para la cesión y el subarriendo, el consentimiento escrito del arrendador, si lo aportado fuese una vivienda ${ }^{88} \mathrm{o}$, en su caso, si se tratara del arrendamiento de una finca urbana en la que se ejerza una actividad empresarial o profesional tampoco resulta aplicable el art. 32 LAU, de manera que no se permitiría que el arrendatario pudiese subarrendarla o ceder el contrato de arrendamiento sin necesidad de contar con el consentimiento del arrendador; tampoco tendrá el arrendador el derecho a elevar la renta (art. 32.2 LAU), ni el arrendatario se verá obligado a notificar fehacien-

85 Idéntica previsión se contiene los artículos 58.6 LCG; 49.7 LCCM; 61.5 LCLR; 64.6 LSCRM; 76.6 LCCLM; 43.4 RLSCA; 48.3 LCAR; y, por último, 49.5 LSCEX. Otras leyes autonómicas no prevén este supuesto (LCPV, LCCyL, LCIB, LCFN, LCCV y LCCAT). A nuestro juicio, esta será la solución óptima, ya que la especialidad prevista en esta materia carece de explicación.

86 En el sentido indicado, vid., Gloria Puy Fernández, «Régimen de las aportaciones al capital social de la cooperativa», REVESCO, n. 67 (1999): 205-206.

87 Así lo señala, Paniagua, La sociedad cooperativa..., 254. Se hace eco de esta opinión, Torres, Régimen..., 79.

88 Nuevamente, Paniagua, La sociedad cooperativa..., 255, quien cita también, para este supuesto, el art. 27.2 c) LAU donde se estipula como causa de resolución por el arrendador la cesión o subarriendo no consentidos. 
temente (art. 32. 4 LAU) la cesión o subarriendo en el plazo de un mes desde su realización ${ }^{89}$.

Por otra parte, en cuanto a los nombres comerciales, marcas, patentes y cualesquiera otros títulos y derechos que constituyesen aportaciones a capital social, considera la doctrina que, con ello, se está refiriendo "como objeto de aportación al derecho de uso de aquellos elementos patrimoniales que la técnica contable denomina "elementos del inmovilizado inmaterial"», "y en concreto a la aportación de derechos de uso sobre nombres comerciales, marcas, patentes, así como sobre otros títulos o derechos que constituyesen aportación social a la cooperativa» ${ }^{90}$.

\section{Conclusiones}

Como se ha podido constatar a lo largo de esta exposición, la normativa española en materia de aportaciones al capital social de la sociedad cooperativa resulta muy confusa y prolija dada la confluencia entre la LC y la regulación resultante de las diferentes leyes autonómicas, lo que no responde adecuadamente a las exigencias de un mercado global como el actual.

En el apartado I., relativo al Estudio Preliminar y Exposición de Motivos, de la Propuesta Articulada de Revisión del Régimen Jurídico de las Cooperativas, presentada en julio de 2017, se alude a la controvertida Sentencia del Tribunal Constitucional de 24 de julio de 1983 donde se renuncia a calificar a las sociedades cooperativas como sociedades mercantiles sentando las bases para la existencia de una pluralidad de leyes de cooperativas autonómicas. Como expresamente se señala en la Propuesta, "lo hizo no sólo en lo que se refiere al régimen jurídico público de control en la vida económica o de promoción y fomento de la cooperación como forma de participación en la empresa, lo que hubiera sido oportuno de acuerdo con lo dispuesto en el artículo 129.2 de la Constitución y con la implantación del movimiento cooperativo en determinadas comunidades autónomas, sino, de manera desafortunada, también por lo que afecta a todo el régimen ju-

89 Citando otros ejemplos suscitados a tenor de la LAR, Ibíd., 255.

90 De este parecer, Puy, «Régimen...», 163, quien se hace eco de la opinión sostenida por Vicent, Ley General..., 239, considerando que con esta previsión se pone fin a la posibilidad de que el titular de esos derechos pueda resolver el contrato por «cesión inconsentida a un tercero». 
rídico de la estructura de esta sociedad» ${ }^{91}$. Por su parte, la Propuesta de la Sección Segunda, de Derecho Mercantil, del Anteproyecto de Ley de Código Mercantil tras el Dictamen del Consejo de Estado (marzo de 2018) hace expresa atribución del carácter mercantil a las sociedades cooperativas, a las mutuas de seguros y a las sociedades de garantía recíproca (art. 211-1, 1) debiendo ser inscritas en el Registro Mercantil.

El régimen arbitrado en el art. 45.4 LC se caracteriza, como así hemos pretendido evidenciar a lo largo de esta exposición, por la complejidad y excesiva cautela con la que son tratadas las aportaciones no dinerarias, mientras que no cabe hacer grandes críticas a la disciplina observada en materia de aportaciones dinerarias. Otra cosa sería el supuesto valorativo de la aportación no dineraria. Así, a la valoración que realicen los fundadores y el consejo rector, se suma, con carácter previo, el informe del experto o expertos independientes y, si así lo disponen los estatutos, a la valoración de los administradores se ha de sumar la posterior aprobación por la asamblea general. No podemos entender cómo para las sociedades cooperativas, aunque se hallen en la frontera entre una economía social y una economía de mercado, se arbitran tantas reservas a tenor de la aportación no dineraria (informe previo del experto, valoración del consejo rector y eventual aprobación por la asamblea general), cautelas que exceden incluso de lo previsto para las sociedades de capital. A este respecto, entendemos plenamente acertado que el régimen de referencia de las aportaciones al capital sea el de las sociedades de capital. Sin embargo, no compartimos que la aproximación deba suceder con prioridad al régimen de la sociedad anónima, sino que consideramos mucho más oportuno que en la regulación, al menos del supuesto valorativo de la aportación no dineraria, el régimen de referencia sea más próximo al de la sociedad de responsabilidad limitada92. Nos referimos, básicamente, a la intervención vin-

91 La doctrina considera que el Tribunal Constitucional, en su Sentencia de 24 de julio de 1983, no estuvo acertado. Vid., como ejemplo, Rosalía Alfonso Sánchez, «Propuesta de Código Mercantil y sociedad cooperativa», Revista Crítica de Derecho Inmobiliario, n. ${ }^{\circ} 744$ (2014): 1663-1716.

$92 \mathrm{Ya}$, con carácter general, se propuso «promover la incorporación de una especialidad en la ley de sociedades de responsabilidad limitada (mercantil por tipo) que regule a las sociedades cooperativas y que, además, sirva de detonante para reconocer a las sociedades cooperativas de hecho». Así es afirmado por Carlos García-Gutiérrez Fernández, "La reafirmación de las aportaciones de (propiedad de) los socios de las sociedades cooperativas. Propuesta de regulación de las sociedades de responsabilidad limitada cooperativa. El incorrecta e impropiamente denominado «capital social» (constituido por las aportaciones financieras propiedad de los socios) en las sociedades cooperativas ante las tentativas de considerarlo «recurso propio». La reafirmación de las aportaciones de (propiedad de) los socios 
culante del experto independiente. Aunque en la LC no se diga nada al respecto, cabe concluir que el consejo rector deberá estar a lo señalado en tal informe. En esta materia, hubiese sido más acertado prever una intervención facultativa del experto independiente y consiguiente exención de la responsabilidad de los administradores aproximándose más al régimen disciplinado en el art. 76 LSC que prevé que los socios de las limitadas cuyas aportaciones no dinerarias hayan sido valoradas por experto independiente quedan excluidos de las responsabilidad por dichas aportaciones entendiendo que tal exclusión opera, fuera de los términos literales del precepto en cuestión, respecto de los restantes responsables solidarios ${ }^{93}$.

Además, la regulación contenida en la LC está plagada de imprecisiones y carencias. No se aclara si el informe del experto independiente es de observancia obligatoria (a nuestro juicio, el informe es absolutamente vinculante); en cuanto al procedimiento de designación del experto, contrasta lo dispuesto en el art. 67 de la LSC, que confiere la designación del experto al registrador mercantil, con la previsión contenida en el art. 45.4 LC en el cual se prevé que la designación sea hecha por el propio consejo rector, de manera que el resultado de esa valoración podría verse comprometido; y, por otra parte, el artículo en cuestión no concreta el círculo de legitimación activa.

A la luz de lo expuesto, el sistema resultante, a tenor de las aportaciones no dinerarias, es excesivamente riguroso. No sólo toma, cuando se habla de la valoración de las aportaciones no dinerarias, como referencia a las sociedades anónimas, sino que cuando se aparta del régimen disciplinado para ellas en la LSC, lo hace ampliando las cautelas establecidas para la aportación no dineraria como si éstas no fuesen suficientes (informe obligatorio de experto independiente y exención de responsabilidad por tales aportaciones, salvo en lo que concierne a la responsabilidad fundacional ${ }^{94}$ ).

Mucho más acertada nos parece la regulación propuesta en la Ponencia para la elaboración de un texto articulado de revisión del régi-

de las sociedades cooperativas», REVESCO, n. ${ }^{\circ} 86$ (2006): 31-32, quien califica de «tendencioso, profuso, complejo, heterogéneo, confuso e inadecuado sistema legislativo cooperativo del estado español de las autonomías sobre lo que es una cooperativa en el mercado global».

93 A este respecto, vid., con ulteriores referencias bibliográficas, Begoña Lagos Rodríguez, Responsabilidad por aportaciones no dinerarias en la sociedad limitada (Navarra: Thomson Reuters-Aranzadi, 2017), 209-212.

94 Vid., párrafo primero del art. 77 LSC: «Los fundadores responderán solidariamente frente a la sociedad, los accionistas y los terceros de la realidad de las aportaciones sociales y de la valoración de las no dinerarias». 
men jurídico de las cooperativas, de 2017. En todo caso, ésta tiene aspectos positivos y otros no tanto. Es el caso del apartado segundo del art. 5.2-1, relativo a la documentación y contenido de las aportaciones, donde se prevé que la admisión de las aportaciones no dinerarias quede sujeta a la previsión estatutaria o a la autorización de la asamblea general, es decir, no sitúa en un plano de igualdad a la aportación dineraria y a la no dineraria, ya que la admisión de ésta se ve supeditada a el cumplimiento de un requisito posterior. Más acertado hubiese sido, a nuestro juicio, que se limitara a establecer el sistema de acreditación de la aportación dineraria para, seguidamente, hacer mención del régimen de valoración de la aportación no dineraria, una vez prevista la constancia en la escritura pública correspondiente de la descripción de tales aportaciones con sus datos registrales, si es que existen, y del valor en euros atribuido a las mismas. Se trataría de evitar el recelo que subyace a la aportación no dineraria frente a la aportación dineraria, pues, con tal previsión, el legislador está mostrando su clara preferencia a tenor de la aportación dineraria.

Por su parte, el apartado primero del art. 5.2-2 de la Propuesta de la Ponencia, relativo a la acreditación de las aportaciones, dispone lo siguiente:

«Las aportaciones dinerarias deberán acreditarse ante el notario autorizante de la escritura, mediante la certificación del depósito de las cantidades correspondientes a nombre de la sociedad en una entidad de crédito o mediante su consignación y entrega en metálico para que aquel constituya el depósito a nombre de la sociedad. Si se tratara de aportaciones no dinerarias se describirán en la escritura de constitución los bienes y derechos aportados con indicación de los datos registrales, si los tuvieran, y el valor de cada uno de ellos».

La solución adoptada en la Propuesta en materia de acreditación de las aportaciones, tanto dinerarias como no dinerarias, nos parece adecuada. Con el régimen descrito se está reproduciendo la regulación característica del sistema de acreditación de la realidad de las aportaciones para las sociedades de capital poniendo fin a la aplicación analógica de la normativa prevista para las sociedades de capital. En esta materia, como en muchas otras, el legislador acude a la LSC.

A tenor del apartado segundo del art. 5.2-2 se establece:

«Las aportaciones no dinerarias deberán ser valoradas por el órgano de administración, al que una vez constituido le corresponderá, también, en su caso, ratificar la valoración que se le haya dado a las aportaciones iniciales por los fundadores. Los miembros del órgano 
de administración serán responsables solidarios frente a la sociedad, a los demás socios y a los terceros, de la realidad y del valor dado a las aportaciones no dinerarias, salvo que su valoración se hubiera sometido al informe de un experto designado por el registrador mercantil del domicilio social.

La acción de responsabilidad prescribe a los cinco años a contar desde el momento en que se hubiera realizado el informe».

La solución que ofrece la Propuesta en materia de valoración de las aportaciones no dinerarias nos parece, en términos generales, acertada. Dos puntos destacan al respecto.

De un lado, los miembros del órgano de administración son responsables de la valoración atribuida a la aportación no dineraria - tanto en el momento constitutivo de la sociedad como en un momento posterior, ya que deberán ratificar la valoración de las aportaciones iniciales de los fundadores- pero, sometiéndose voluntariamente a la valoración pericial, se eximen de responsabilidad. Que la existencia de una valoración pericial no sea preceptiva y que de existir un sometimiento voluntario al informe del experto independiente los administradores se eximan de responsabilidad parece lógico, puesto que la intervención del experto refuta toda necesidad de exigencia de responsabilidad en la materia. De esta forma, la Propuesta parece que se está aproximando más a las sociedades de responsabilidad limitada que a las sociedades anónimas, ya que, con buen criterio, desaparece toda previsión obligatoria de informe de experto independiente y se prevé la voluntariedad del informe con la consecuente exención de responsabilidad. En tal caso, dado que no es tarea del experto verificar la realidad de la aportación no dineraria, sino que su cometido se circunscribe a la valoración de ésta, siempre habría de subsistir la responsabilidad de los legitimados pasivamente por la realidad de la aportación no dineraria. En todo caso, el informe del experto independiente debiera, a nuestro juicio, de eximir de toda responsabilidad a los administradores siempre que se mantuvieran en lo estipulado por tal informe y salvo supuestos de connivencia entre los administradores o, en su caso, los fundadores y el experto independiente lo que determinaría la existencia de una responsabilidad compartida.

De otro, se elimina toda previsión estatutaria que disponga la posterior aprobación por la asamblea general de la valoración conferida a la aportación no dineraria por el consejo rector. Ello, sin duda, resulta muy oportuno, ya que tal aprobación no desplaza, como así se refirió en su momento, la responsabilidad de los administradores.

Por último, si como legitimado pasivamente se halla el administrador social, que deberá ratificar la valoración que se haya dado a las 
aportaciones iniciales por los fundadores, en cuanto a la legitimación activa prevé la Propuesta que esta recaiga sobre la sociedad, los socios y los terceros. A este respecto, entendemos que la atribución de legitimación al tercero suscita la posibilidad, dada la ambigüedad del término, de una interpretación extensiva de éste, de manera que todo aquel que se encuentre en una «relación de negocios» con la sociedad pueda resultar legitimado, aunque es cierto que el tercero interesado normalmente coincidirá con el acreedor social. A nuestro juicio, hubiese sido más acertado que la legitimación activa pesara sobre la sociedad, los demás socios y los acreedores sociales considerando que, en el caso de insolvencia de la cooperativa, debiera resultar legitimado activamente cualquier acreedor social.

\section{Bibliografía}

ALFONSO SÁNCHEZ, Rosalía. 2014. «Propuesta de Código Mercantil y sociedad cooperativa», Revista Crítica de Derecho Inmobiliario, n. ${ }^{\circ}$ 744: 1663-1716.

ALFONSO SÁNCHEZ, Rosalía et al., 2001. La Sociedad Cooperativa en la ley 27/1999, de 16 de julio, de Cooperativas. Granada: Comares.

ALONSO PÉREZ, Mariano. 1972. El riesgo en el contrato de compraventa. Madrid: Montecorvo.

ATXABAL RADA, Alberto. 2018. "Los impuestos personales sobre el capital en las cooperativas y en sus socios en el País Vasco». Boletín de la Asociación Internacional de Derecho Cooperativo 52: 137-166. doi: http://dx.doi. org/10.18543/baidc-52-2018pp137-166.

ÁVILA DE LA TORRE, Alfredo. 2006. "Aspectos jurídico-mercantiles de la Sociedad Cooperativa. Breves consideraciones», en Morgado Panadero (dir.), Economía social y cooperativismo, 79-103. Valladolid: Lex Nova.

BERCOVITZ ÁLVAREZ, Raúl. 1999. La aportación de derechos de propiedad industrial al capital de las sociedades anónimas. Breve referencia a esta aportación en las sociedades limitadas. Navarra: Aranzadi.

BÉRGAMO, Alejandro. 1970. Sociedades Anónimas. Las acciones, Tomo I. Madrid: Prensa Castellana S.A.

BONARDELL LENZANO, Rafael y CABANAS TREJO, Ricardo. 2009. «De las aportaciones y de las adquisiciones onerosas», en Arroyo Martínez, Embid Irujo y Górriz López (coords.), Comentarios a la Ley de Sociedades Anónimas, vol. I, 417-473. Madrid: Tecnos.

CÁMARA ÁLVAREZ, Manuel de la. 1996. El capital social en la sociedad anónima, su aumento y disminución. Madrid: Consejo General del Notariado.

CARRAU CARBONELL, José María. 2017. «Aportaciones sociales», en Ballester Azpitarte (coord..), Tratado de sociedades de Capital: comentario judicial, notarial, registral y doctrinal de la Ley de Sociedades de Capital (Arts. 1 a 316), Tomo I, 385-431. Navarra: Thomson Reuters Aranzadi. 
DÍAZ GÓMEZ, María Angustias. 1997. Las aportaciones no dinerarias en la Sociedad Anónima: contenido, valoración y desembolso. Madrid: McGrawHill Interamericana de España.

ESPERANZA MARTíNEZ-RADIO, Antonio de la. 1960. «Tradición instrumental y aportación social», RDM, n. ${ }^{\circ} 78:$ 457-492.

FAJARDO GARCÍA, Gemma. 2015. «Orientaciones y aplicaciones del principio de participación económica», CIRIEC-España, Revista de Economía Pública, Social y Cooperativa, n. ${ }^{\circ}$ 27: 205-242.

FERNÁNDEZ FERNÁNDEZ, Inés. 1997. Aportaciones no dinerarias en la sociedad anónima. Navarra: Aranzadi.

GALLEGO SÁNCHEZ, Esperanza. 1995. «Las aportaciones en la sociedad de responsabilidad limitada», $R d S$, n. ${ }^{\circ}$ 5: 79-130.

GALLEGO SÁNCHEZ, Esperanza. 2011. "Acreditación de la realidad de las aportaciones», en Rojo Fernández Río y Beltrán Sánchez (dirs.), Comentario de la Ley de Sociedades de Capital, Tomo I, 586-595. Navarra: Thomson Reuters-Civitas.

GAMINDE EGIA, Eba. 2018. "Régimen jurídico de la participación de los socios y socias en el capital de la cooperativa: tipos de aportación y derechos económicos». Boletín de la Asociación Internacional de Derecho Cooperativo 53: 207-224. doi: http://dx.doi.org/10.18543/baidc-532018pp207-224.

GAMINDE EGIA, Eba. 2017. "Las altas de los/as socios/as en las sociedades cooperativas». Boletín de la Asociación Internacional de Derecho Cooperativo 51: 191-208. doi: http://dx.doi.org/10.18543/baidc-512017pp191-208.

GARCÍA-GUTIÉRREZ FERNÁNDEZ, Carlos. 2006. «La reafirmación de las aportaciones de (propiedad de) los socios de las sociedades cooperativas. Propuesta de regulación de las sociedades de responsabilidad limitada cooperativa. El incorrecta e impropiamente denominado «capital social» (constituido por las aportaciones financieras propiedad de los socios) en las sociedades cooperativas ante las tentativas de considerarlo "recurso propio». La reafirmación de las aportaciones de (propiedad de) los socios de las sociedades cooperativas», REVESCO, Revista de Estudios CooperatiVOS, n. ${ }^{\circ}$ 86: 27-32.

GARRIDO DE PALMA, Víctor Manuel. 1997. «Régimen de las aportaciones sociales», en Cándido Paz-Ares (coord.), Tratando de la sociedad de responsabilidad limitada, 359-392. Madrid: Fundación Cultural del Notariado.

GARRIGUES, Joaquín. 1947. Tratado de Derecho Mercantil, Tomo I, vol. 1.. Madrid: Revista de Derecho Mercantil.

GARRIGUES, Joaquín. 1974. "Teoría general de las sociedades mercantiles», $R D M$, n. ${ }^{\circ} 132: 181-254$.

GENOVART BALAGUER, Juana Isabel y MAULEÓN MÉNDEZ, Emilio. 2017. «La repercusión económico-contable de la baja del socio en la sociedad cooperativa: la incidencia de la NIC 32». Boletín de la Asociación Internacional de Derecho Cooperativo 51: 99-134. doi: http://dx.doi.org/10.18543/ baidc-51-2017pp99-134. 
GIRÓN TENA, José. 1976. Derecho de Sociedades, Tomo. I, Parte general, sociedades colectivas y comanditarias. Madrid: GT.

LAGOS RODRÍGUEZ, Begoña. 2017. Responsabilidad por aportaciones no dinerarias en la sociedad limitada. Navarra: Thomson Reuters-Aranzadi.

LOJENDIO OSBORNE, Ignacio. 1994. "Aportaciones sociales (artículos 36 a 41 LSA)», en Uría, Menéndez y Olivencia (dirs.), Aportaciones sociales y dividendos pasivos, artículos 36 a 46 de la Ley de Sociedades Anónimas, Tomo III, vol. 3. ${ }^{\circ}, 15-227$. Madrid: Civitas.

LOJENDIO OSBORNE, Ignacio. 1999. "Aportaciones sociales (artículos 18 a 21 LSRL)», en Uría, Menéndez y Olivencia, Régimen Jurídico de la Sociedad de Responsabilidad Limitada, Tomo XIV, vol. 1. A, 515-603. Madrid: Civitas.

LÓPEZ JACOISTE, José Javier. 1955. El arrendamiento como aportación del socio. Navarra: Ed. Uni. Navarra.

LLOBREGAT HURTADO, María Luisa. 1990. Mutualidad y empresas cooperativas. Barcelona: Librería Bosch.

MAMBRILLA RIBERA, Vicente. 1991. «Fundación con aportaciones in natura», en Alonso Ureba (coord.), Derecho de Sociedades Anónimas, Tomo I, La fundación, 729-774. Madrid: Civitas.

MATA DIESTRO, Héctor. 2018. «Fondos sociales obligatorios: la justificación de su irrepartibilidad en los orígenes del cooperativismo y del movimiento obrero organizado». Boletín de la Asociación Internacional de Derecho Cooperativo 53: 289-307. doi: http://dx.doi.org/10.18543/baidc-53-2018pp289-307.

MORILLAS JARILLO, María José y FELIÚ REY, Manuel Ignacio. 2018. Curso de Cooperativas, Tomo I. Madrid: Tecnos.

OLIVIERI, Gustavo. 1989. I conferimenti in natura nella società per azioni. Padova: Cedam.

PANIAGUA ZURERA, Manuel. 2005. La sociedad cooperativa. Las sociedades mutuas de seguros y las entidades mutuales de previsión social. Madrid: Marcial Pons.

PASTOR SEMPERE, María del Carmen. 2002. Los recursos propios en las sociedades cooperativas. Madrid: EDERSA.

PENDÓN MELÉNDEZ, Miguel Ángel. 2019. «El capital social. Aportaciones al capital social», en Peinado Gracia (dir.), Tratado de Derecho de sociedades cooperativas, Tomo I, 682-752. Valencia: Tirant lo Blanch.

PÉREZ DE LA CRUZ, Antonio. 1973. La reducción del capital social en sociedades anónimas y de responsabilidad limitada. Zaragoza: Real Colegio de España en Bolonia.

PUY FERNÁNDEZ, Gloria. 1999. «Régimen de las aportaciones al capital social de la cooperativa», REVESCO, Revista de Estudios Cooperativos, n. ${ }^{\circ} 67$ : 187-217.

RUBIO VICENTE, Pedro José. 2001. La aportación de empresa en la sociedad anónima. Valladolid: Lex Nova.

TORRES PÉREZ, Francisco José. 2012. Régimen jurídico de las aportaciones sociales en la sociedad cooperativa. Navarra: Aranzadi.

URÍA GONZÁLEZ, Rodrigo y MENÉNDEZ MENÉNDEZ, Aurelio. 1999. Curso de Derecho Mercantil, I. Madrid: Civitas. 
VALENZUELA GARACH, Francisco Javier. 2019. «El capital social. Aportaciones que no forman parte del capital social», en Peinado Gracia (dir.), Tratado de derecho de sociedades cooperativas, Tomo I, 752-767. Valencia: Tirant lo Blanch.

VALPUESTA GASTAMINZA, Eduardo. 2015. Comentarios a la Ley de Sociedades de Capital: estudio legal y jurisprudencial. Barcelona: Bosch.

VARGAS VASSEROT, Carlos. 2015. «El principio cooperativo de puertas abiertas (adhesión voluntaria y abierta). Tópico o realidad en la legislación y en la práctica societaria», CIRIEC-España, Revista jurídica de economía social y cooperativa, n. ${ }^{\circ}$ 27: 133-174.

VARGAS VASSEROT, Carlos, GADEA SOLER, Enrique y SACRISTÁN BERGIA, Fernando. 2015. Derecho de las sociedades cooperativas. Introducción, constitución, estatuto del socio y órganos sociales. Madrid: La Ley.

VICENT CHULIÁ, Francisco. 1972. "Análisis crítico del nuevo Reglamento de Cooperación (Decreto 2396/1971 de 13 de agosto. «B.O.E.» de 9 de octubre)», RDM, n. ${ }^{\circ}$ 125-126: 429-538.

VICENT CHULIÁ, Francisco. 1991. Compendio crítico de Derecho Mercantil, Tomo I. Barcelona: J. M. Bosch.

VICENT CHULIÁ, Francisco. 1994. Ley General de Cooperativas, vol. 3. ․ Artículos 67 al final. Madrid: EDERSA. 


\section{Derechos de autor}

El Boletín de la Asociación Internacional de Derecho Cooperativo es una revista de acceso abierto lo que significa que es de libre acceso en su integridad inmediatamente después de la publicación de cada número. Se permite su lectura, la búsqueda, descarga, distribución y reutilización legal en cualquier tipo de soporte sólo para fines no comerciales y según lo previsto por la ley; sin la previa autorización de la Editorial (Universidad de Deusto) o el autor, siempre que la obra original sea debidamente citada (número, año, páginas y DOI si procede) y cualquier cambio en el original esté claramente indicado.

\section{Copyright}

The International Association of Cooperative Law Journal is an Open Access journal which means that it is free for full and immediate access, reading, search, download, distribution, and lawful reuse in any medium only for non-commercial purposes, without prior permission from the Publisher or the author; provided the original work is properly cited and any changes to the original are clearly indicated. 